\title{
əHymec: Surface Precipitation Type Estimation at the German Weather Service
}

\author{
Jörg Steinert, ${ }^{\mathrm{a}}$ PAtrick Tracksdorf, ${ }^{\mathrm{a}}$ AND Dirk HeIzenreder ${ }^{\mathrm{a}}$ \\ ${ }^{\mathrm{a}}$ Deutscher Wetterdienst, Offenbach am Main, Germany
}

(Manuscript received 15 December 2020, in final form 22 June 2021)

\begin{abstract}
The analysis and forecast of precipitation characteristics is a key task for national meteorological services for providing high-quality weather forecasts and warnings. Beside the precipitation amount, the precipitation type is essential to describe and evaluate the recent, ongoing, and future weather situations. This paper introduces a new surface-based hybrid hydrometeor classification algorithm. The presented method combines polarimetric radar observations at radar beam height from the C-band dual-polarization weather radar network of the German Weather Service [Deutscher Wetterdienst (DWD)] with corrected thermodynamical profiles of numerical weather prediction (NWP) model output and extrapolates the hydrometeor classes at radar beam height to a height of $2 \mathrm{~m}$ above ground level (AGL). The implemented technique parameterizes the microphysical processes in the lower troposphere based on the appropriate thermodynamical profile that the hydrometeors have to pass along their way from the radar beam height to the surface. Due to errors in NWP output, the NWP vertical profiles of temperature and humidity are adjusted by using several types of surface stations with high spatial and temporal resolution. Verification results show considerable improvements in the hydrometeor classification near the ground compared to the radar sweep height. After an additional positive in-house evaluation, the presented method is integrated into DWD's operational environment. The topic of this paper is to describe the processing steps for the computation of the near-surface precipitation type. In addition, example cases and a verification study complement the explanations.

SIGNIFICANCE STATEMENT: For a national weather service and its customers, the separation of precipitation types into solid and liquid is a key issue for improving weather forecasts and warnings. We combined measurements from weather radars and weather stations together with output of numerical weather prediction models and developed a method of estimating the precipitation type at a height of $2 \mathrm{~m}$. Previous studies of the hydrometeor classification field concentrate on warm season weather conditions using "radar observations only" or apply a hybrid combination of radar observations with model information. The uniqueness of our work is the additional introduction of surface observations with high temporal and spatial resolution for a better estimation of the thermodynamical profiles to improve the "all season alignment."
\end{abstract}

KEYWORDS: Hydrometeorology; Thermodynamics; Radars/Radar observations; Surface observations; Operational forecasting

\section{Introduction}

The weather forecasting and warning process consists of several components including observation, nowcasting and ensemble-based numerical weather prediction (NWP). The analysis and forecast of precipitation type during winter is one of the challenges for forecasters of national meteorological services especially in severe weather situations. There are many other domains (e.g., civil protection, transport sector) that have an increasing demand for reliable precipitation type information. The type of precipitation is also a key part of weather reports and severe weather alerts and therefore influences the messaging of weather hazards and the associated public response. There are some meteorological instruments that allow an estimation or observation of the precipitation type, such as weather stations (Bloemink and Lanzinger 2005), weather radars (Park et al. 2009), or other sensors like radiosondes (Keeter and Cline 1991). In particular, weather radars

¿ Denotes content that is immediately available upon publication as open access.

Corresponding author: Jörg Steinert, joerg.steinert@dwd.de allow a large areal coverage with a high temporal and spatial resolution, but have the drawback that the data are valid for the height and path of the radar beam only. Automated weather stations deliver measurements with high temporal resolution from different sensors near the surface [commonly $2 \mathrm{~m}$ above ground level (AGL)] but have the drawback of being "point sources" valid for a small region only. As a result, the estimation of a near-surface precipitation type in a suitable spatial and temporal resolution necessitates the fusion of information from various data sources (Zhang et al. 2011, 2016). Especially in the winter season, the precipitation type near the ground strongly depends on the thermodynamical profiles in the lower troposphere so that an exclusive use of weather radar data is not adequate for this purpose. Unfortunately, the availability of meteorological measurements for the region between the radar measurements and the surface is very sparse. The utilization of high-quality measurements from radiosondes is not feasible, as there are only a few stations with a poor temporal resolution available. So, the output of NWP models is applied as a substitute.

This article is licensed under a Creative Commons Attribution 4.0 license (http://creativecommons.org/ licenses/by/4.0/). 
Several surface-based precipitation-type algorithms have been developed considering the aforementioned issues (Ramer 1993; Baldwin et al. 1994; Bourgouin 2000; Schuur et al. 2012). A common approach is the Boolean decision tree that was used in Ramer (1993) and Baldwin et al. (1994) with a focus on the NWP vertical profile of the wet-bulb temperature. Bourgouin (2000) invented a statistical algorithm that utilized the area above or below the freezing layer and produced better results for the estimated precipitation type. In the hybrid method of Schuur et al. (2012), weather radar measurements were added to the NWP based classification to refine the results. Reeves et al. (2014) used observed and model-forecast sounding data to evaluate the performance of these algorithms. The authors identified the errors of the model used to estimate the thermodynamic profiles in the lower troposphere as an important source of uncertainty of the precipitation type algorithms.

While Schuur et al. (2012) included weather radar measurements and presented an NWP-model-based method, Schuur et al. (2014) went further by showing the positive influence of the integration of a radar-based hydrometeor classification. For this, Schuur et al. (2014) took the hydrometeor classification of the WSR-88D network (Park et al. 2009). In a recent study, Yang et al. (2021) also suggest the integration of weather radar measurements to improve NWP model data based precipitation type estimations. The authors link to the findings of Schuur et al. (2012) and Schuur et al. (2014) and started with a radar-based hydrometeor classification algorithm. The research in such algorithms started decades ago and is strongly connected to dualpolarization (dualpol) radar measurements and their relation to specific hydrometeor types (Straka et al. 2000). Approximately 10 years ago, national meteorological services began to upgrade or renew their weather radar networks with dualpol radar systems. With this step, they also implemented hydrometeor classification algorithms to profit from the dualpol data (e.g., Park et al. 2009; Al-Sakka et al. 2013).

The method described here is named hydrometeor classification (Hymec) to draw attention to the origin of the developments. The building blocks are a hydrometeor classification [Hymec radar sweep (HymecRS)] and an algorithm to extrapolate the hydrometeor classes onto the height of $2 \mathrm{~m}$ AGL [Hymec near ground (HymecNG)]. For the initial setup of HymecRS, the parameterization of Park et al. (2009) was applied. Although Park et al. (2009) tuned the hydrometeor classification for weather radar systems operating at the S-band frequency range, they are a valid starting point with respect to the need of adjusting to the C-band frequency range (e.g., AlSakka et al. 2013). To reduce the impact of the model error in the surface-based precipitation type detection algorithm this paper introduces additional improvements, taking surface observations with a high temporal resolution into account. HymecNG uses thermodynamic profiles of the wet-bulb temperature and applies a Boolean decision tree to the so-called melting area (cf. area model in Bourgouin 2000). The adaptation of the setup was done by its application in several case studies and the utilization of feedback from in-house forecasters in recent years.

The structure of the paper is as follows. Section 2 starts with an overview of the data sources and a summary of their specific

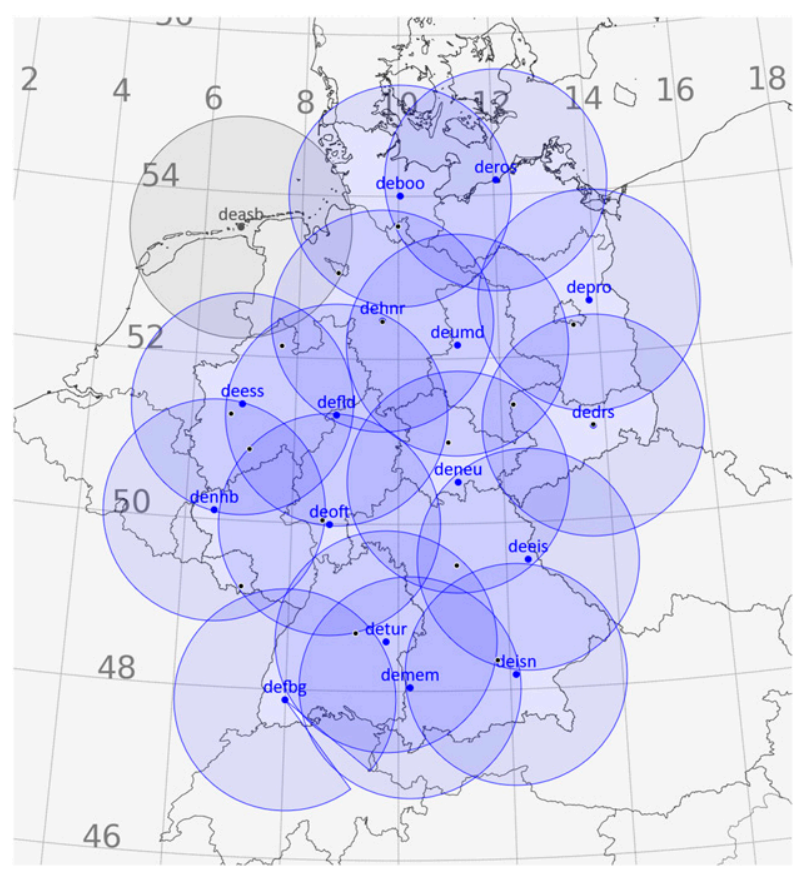

FIG. 1. Operational DWD weather radar network shown with a 150-km coverage radius: dualpol system (blue) and singlepol system (gray). Black dots: locations of the disdrometer that are used for verification. (Environmental data: (c) GeoBasis-DE/BKG $<2015>$ ).

characteristics. The procedure for analyzing weather radar measurements, namely HymecRS, is elucidated in section 3 . Section 4 deals with the description of the method for extrapolating the radar derived hydrometeor classes to get the precipitation type at a height of $2 \mathrm{~m}$ AGL. Furthermore, a verification study of the estimated precipitation type has been done and some prominent verification measures are presented in section 5 . The paper concludes in section 6 with a summary of the findings and a discussion about potential future tasks in this field.

\section{Instruments and data pool}

The database for the analysis of the precipitation type consists of measurements from the weather radar network of the German Weather Service [Deutscher Wetterdienst (DWD)] (Helmert et al. 2014), reports from weather stations and output from the NWP model COSMO-D2 (Baldauf et al. 2018) to complement the situation in regions where no observations are available. In addition, disdrometers are used as an independent verification source.

\section{a. Weather radar measurements}

Weather radars are appropriate remote sensing devices for analyzing the microphysical structure of precipitation with a high spatial coverage. Hence, the DWD, as the national weather service of Germany, operates a network composed of 17 C-band weather radar systems (see Fig. 1 and Helmert et al. 2014). During algorithm development and verification, 16 radar systems are equipped with dualpol capability (type: EEC 
DWSR-5001C/SDP-CE) and one radar uses the singlepolarization (singlepol) technique. Because of this, the main data processing focus is on dualpol radar measurements with a fallback to analyzing singlepol data. Especially for the estimation of the precipitation type, the application of dualpol radar data gives a valuable improvement (e.g., Park et al. 2009). Regarding the operation in simultaneous horizontal and vertical transmission (Scott et al. 2001) the available set of radar quantities include, among others, the reflectivity in horizontal polarization $Z_{H}(\mathrm{~dB} Z)$, the differential reflectivity $Z_{\mathrm{DR}}$ $(\mathrm{dB})$, the copolar correlation coefficient $\rho_{\mathrm{HV}}$ as a scalar quantity, and the specific differential phase $K_{\mathrm{DP}}\left({ }^{\circ} \mathrm{km}^{-1}\right)$. These quantities are helpful for a hydrometeor classification because they give information about the precipitation intensity ( $Z_{H}$ and $\left.K_{\mathrm{DP}}\right)$, the hydrometeor shape $\left(Z_{\mathrm{DR}}\right)$ and the conformity of the particles inside the measurement volume $\left(\rho_{\mathrm{HV}}\right)$ (cf. Straka et al. 2000).

Due to the operation in a $24 / 7$ environment, the radar systems follow a fixed and congruent scan sequence. In summary, there are 11 plan position indicator (PPI) scans from each radar system that are repeated every $5 \mathrm{~min}$. Though the presented hydrometeor classification may be applied to each scan, only the "precipitation scan" with a low antenna elevation is used. The specialty of this PPI is that it has no fixed elevation angle, since the radar beam roughly follows the orography, resulting in higher elevations when the radar points to mountainous regions. The default elevation is $0.8^{\circ}$ and it is adjusted up to $1.9^{\circ}$ for the radar system Memmingen, see "demem" in Fig. 1, in the direction of the Alps. The recorded range resolution of this scan is $250 \mathrm{~m}$. The other 10 PPI scans satisfy the need of measurements at higher altitudes. The fixed elevation angles of these scans are $0.5^{\circ}, 1.5^{\circ}, 2.5^{\circ}, 3.5^{\circ}, 4.5^{\circ}, 5.5^{\circ}, 8^{\circ}, 12^{\circ}, 17^{\circ}$, and $25^{\circ}$ and they are provided in a $1-\mathrm{km}$ range resolution.

To get an impression of the height difference between the measuring height of the precipitation scan and a height of $2 \mathrm{~m}$ AGL a composite plot is displayed in Fig. 2. The values range from $0 \mathrm{~km}$ at the location of the radar sites up to more than $4 \mathrm{~km}$ at Alpine valleys in the southern part of Germany and also far from the radar site.

\section{b. NWP model output}

Due to the lack of high-resolution meteorological measurements, NWP model output on a 3D grid is applicable for the analysis of the wet-bulb temperature profiles. Difficulties arise with the arrangement of the output, as the NWP model provides data on a discrete grid with a low temporal resolution in contrast to areal weather radar measurements, see section 2a. The applied NWP model is the COSMO-D2 (Baldauf et al. 2018), a regional model that is convection resolving by using an adapted version of the mass-flux convection scheme of Tiedtke (1989). A summary of the physical parameterizations of COSMO models is given in Doms et al. (2011). Briefly, the radiation is parameterized by the $\delta$ two-stream method of Ritter and Geleyn (1992), the parameterization of the microphysics includes water vapor, cloud water, cloud ice, rain, snow and graupel (Seifert 2002), and for data assimilation the local ensemble transform Kalman filter (LETKF) is applied (Schraff et al. 2016). COSMO-D2 output has a horizontal

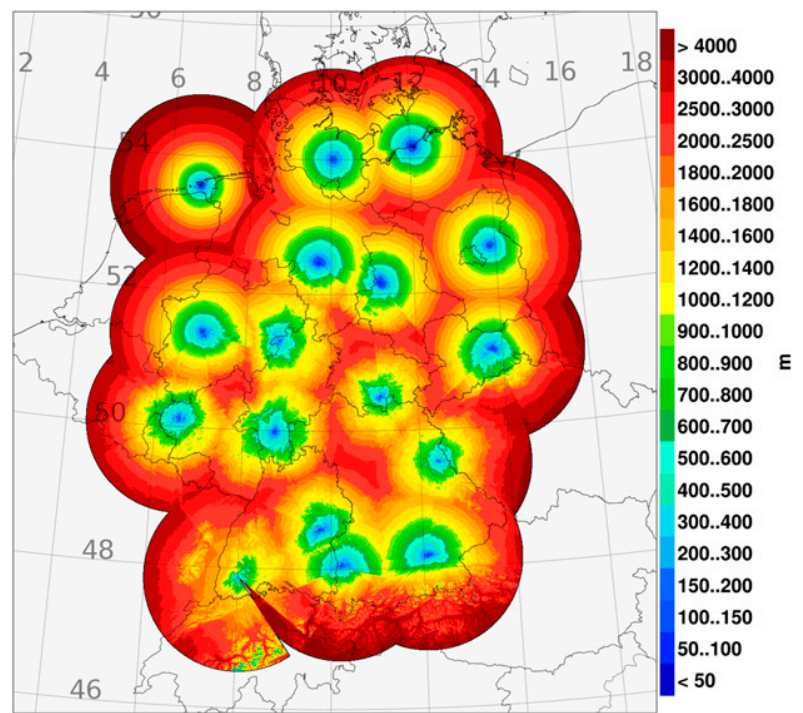

FIG. 2. Operational DWD weather radar network: Height difference in $\mathrm{m}$ between a height of $2 \mathrm{~m}$ AGL and the measurement height of the terrain following "precipitation scan." (Environmental data: (c) GeoBasis-DE/BKG<2015>).

grid spacing of $2.2 \mathrm{~km}$ and a vertical resolution of 65 layers. Furthermore, the top layer is equivalent to a height of $22 \mathrm{~km}$ and the lowest layer corresponds to a height of $10 \mathrm{~m}$ AGL. The model domain covers the whole territory of Germany, Austria, Switzerland, Benelux, and parts of the neighboring countries. This implies that the COSMO-D2 domain is larger than the coverage of DWD's radar network and so every weather radar measurement can be combined with NWP output. COSMOD2 is initialized every $3 \mathrm{~h}$ and produces output for every hour going out to forecast hour 27. Distinctive single layer parameters, such as the height of the $0^{\circ} \mathrm{C}$ isotherm and the height of the snow line, may also be provided in forecasts with a 15-min resolution. Among others, COSMO-D2 provides the vertical profiles of the temperature $T(\mathrm{~K})$, the specific humidity $q\left(\mathrm{~kg} \mathrm{~kg}^{-1}\right)$, and the pressure $p(\mathrm{~Pa})$. Furthermore, the 2D field of the height of the transition between precipitation as snow above and as rain below, $h_{\text {snowline }}(\mathrm{m}$ above mean sea level), is provided, see Table 1.

\section{c. Weather station reports}

The DWD operates a network of 182 automated official weather stations (OWS). Any OWS consists of several standardized sensors placed on a suitable measuring field, following the guidelines of the World Meteorological Organization (WMO). The heights of the measuring fields across Germany range from $-0.27 \mathrm{~m}$ above mean sea level (MSL) for the station Emden (North Sea coast) to $2964.5 \mathrm{~m}$ MSL for the station Zugspitze (the Alps). The measurements relevant to our project are the air temperature $T(\mathrm{~K})$, the relative humidity $\mathrm{RH}(\%)$, and the pressure $p(\mathrm{~Pa})$, whereby the three associated sensors are located at $2 \mathrm{~m}$ AGL. The OWS deliver the measurements with a temporal resolution of $10 \mathrm{~min}$. An evaluation of manual and automatic (operational) measurements carried 
TABLE 1. Relevant COSMO-D2 NWP model output variables.

\begin{tabular}{|c|c|c|c|c|c|}
\hline COSMO-D2 identifier & Quantity & Description & Unit & Vertical layers & Temporal resolution \\
\hline SNOWLMT & $h_{\text {snowline }}$ & $\begin{array}{l}\text { Level with precipitation as snow above and } \\
\text { rain below }\end{array}$ & $\mathrm{m}$ & 1 & $15 \mathrm{~min}$ \\
\hline $\mathrm{T}$ & $T$ & (Dry-bulb) temperature & $\mathrm{K}$ & 65 & $1 \mathrm{~h}$ \\
\hline QV & $q$ & Specific humidity & $\mathrm{kg} \mathrm{kg}^{-1}$ & 65 & $1 \mathrm{~h}$ \\
\hline $\mathrm{P}$ & p & Pressure & $\mathrm{Pa}$ & 65 & $1 \mathrm{~h}$ \\
\hline WW & Weather code & $\begin{array}{l}\text { Precipitation type (see World Meteorological } \\
\text { Organization 2019, code table 4677) for a } \\
\text { height of } 2 \mathrm{~m} \mathrm{AGL}\end{array}$ & - & 1 & $1 \mathrm{~h}$ \\
\hline
\end{tabular}

out in parallel is given in Augter (2013), Hannak and Brinckmann (2020). We use the data directly without any additional quality checks, as there is a continuous operational monitoring of the OWS.

Furthermore, measurements from almost 1500 road weather stations (RWS) are available to extend the availability of meteorological measurements near the ground. These stations are operated by the German Federal States directly on freeways and federal highways. Due to the "rough conditions," these measuring fields do not adhere to the guidelines of the WMO (e.g., distance to buildings). The heights of the RWS across Germany range from $0 \mathrm{~m}$ MSL for the station Carolinensiel (North Sea coast) to $1148 \mathrm{~m}$ MSL for the station Oberjoch (the Alps). The RWS deliver measurements with a temporal resolution of $15 \mathrm{~min}$. Unfortunately, a sensor for air pressure is not present. Nevertheless, we use the air temperature and the relative humidity. The RWS undergo an in-house developed quality assurance (QA) procedure to suppress erroneous data (e.g., by checking for strong differences between data of neighboring stations). The QA is based on DIN EN 15518-3: 2011-04 (2011) and FGSV (2019) and rejects approximately $5 \%$ of the RWS measurements.

Hereafter, OWS as well as RWS will be referred to as weather stations (WS) unless a specific label is needed. Figure 3 gives a graphical overview of the locations for both types of stations with red dots for OWS and blue dots for RWS.

\section{d. Disdrometer measurements}

The DWD station network also includes disdrometers at airports. Because their measurements are not involved in the implemented Hymec algorithms, they are a suitable source for verification of the estimated precipitation type. The disdrometers are located at 15 airports (see black dots in Fig. 1). They count the precipitation particles by using a laser band. Hence, they are called laser precipitation monitors (LPM) (see Bloemink and Lanzinger 2005). In addition, two LPM are available at each airport, which doubles the allocatable time series for ground truth. Beside the drop size spectra, the LPM also delivers the estimated weather code at a 1-min time resolution, which provides the foundation for our verification base.

\section{HymecRS}

With the help of the weather radar measurements from DWD's weather radar network (see Fig. 1) the Hymec algorithm collection has been built since 2010. A current overview of the Hymec components is displayed in Fig. 4 together with the link to the used data types. As an illustration, the figure shows sketched classification results from synthetic data. A key algorithm is the hydometeor classification at radar sweep height HymecRS.

The method of Park et al. (2009) forms the basis for HymecRS. They presented a fuzzy-logic hydrometeor classification algorithm (HCA) for the U.S. WSR-88D S-band radar systems. Besides the discrimination in hydrometeor classes for dry aggregated snow, wet snow, crystals of various orientations, graupel, big drops, light and moderate rain, heavy rain and a mixture of rain and hail, classes for nonmeteorological echoes, such as ground clutter, anomalous propagation and biological scatterers are addressed. The HCA applies the radar quantities $Z_{H}, Z_{\mathrm{DR}}, \rho_{\mathrm{HV}}, K_{\mathrm{DP}}$ and texture parameters of $Z_{H}$ and the differential phase $\Phi_{\mathrm{DP}}$ to handle small-scale variations of the two quantities. A specialty in the HCA is the use of

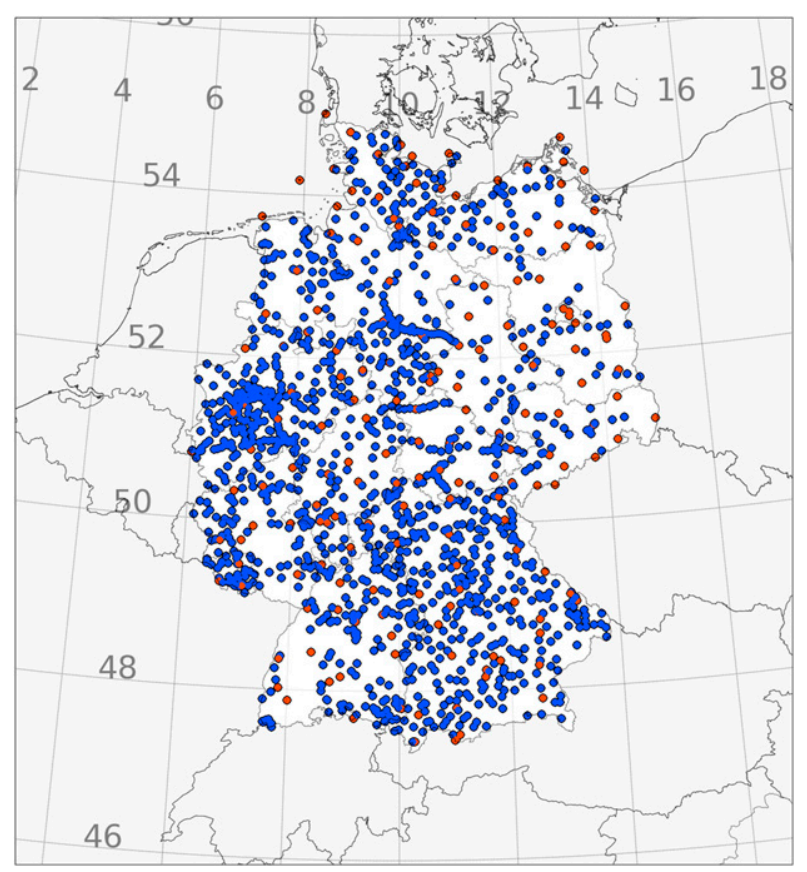

FIG. 3. Locations of utilized weather stations. Red: official weather stations with nearly regular distribution. Blue: road weather stations at freeways and federal highways. (Environmental data: (c) GeoBasis-DE/BKG $<2015>$ ). 


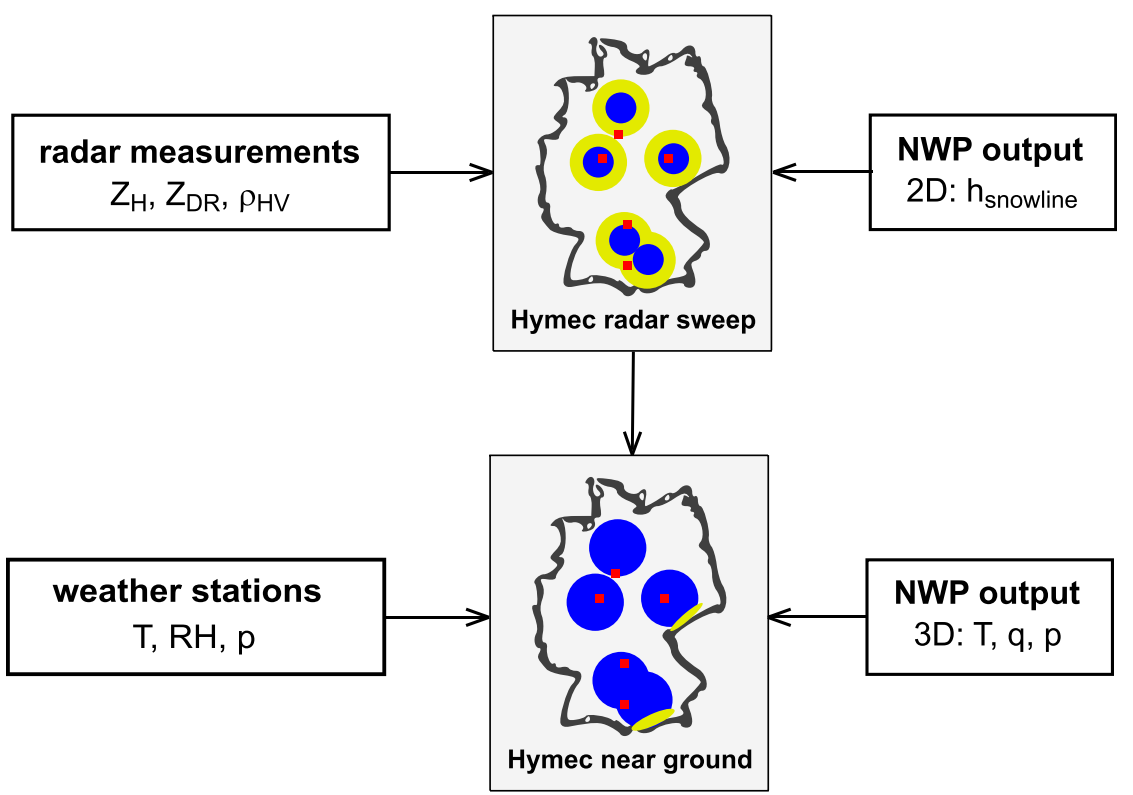

FIG. 4. Sketch of the Hymec algorithm set. The images highlight the classification steps with synthetic data for the selected precipitation types: rain in blue, snow in yellow, and hail in red. (top) Algorithm with focus on radar measurements for hydrometeor classification (HymecRS, section 3); (bottom) extrapolation algorithm for precipitation type estimation (HymecNG, section 4).

two-parameter trapezoidal membership functions (MBF) for hydrometeor classes with liquid phase particles. The relationships from Park et al. [2009, their Eq. (4)] are

$$
\begin{aligned}
& f_{1}\left(Z_{H}\right)=-0.5+0.0025 Z_{H}+0.00075 Z_{H}^{2}, \\
& f_{2}\left(Z_{H}\right)=0.68-0.0481 Z_{H}+0.00292 Z_{H}^{2}, \\
& f_{3}\left(Z_{H}\right)=1.42+0.0667 Z_{H}+0.000485 Z_{H}^{2},
\end{aligned}
$$

with $Z_{H}$ in $\mathrm{dB} Z$. The parameters $f_{1}, f_{2}$, and $f_{3}$ are helper quantities to configure the MBF thresholds for $Z_{\mathrm{DR}}$. Park et al. (2009) characterized the quality of the radar measurements (e.g., miscalibration, attenuation) by a confidence vector. In addition to the HCA, they invented the melting layer detection algorithm (MLDA) to sort out obviously wrong allocations (e.g., rain above melting layer).

HymecRS provides a separation into the following hydrometeor classes addressing the user requirements at DWD:

- drizzle

- rain

- big drops*

- dry snow

- wet snow*

- ice crystals*

- graupel*

- dry hail

- wet hail*

- large dry hail*

The marked classes $(*)$ are only available with dualpol radar data while the others are served with both singlepol and dualpol radar quantities. The reduction of the envisaged hydrometeor classes in the singlepol case relates to a lower classification quality when only $Z_{H}$ is available. To facilitate the recalculation for historical data from singlepol systems, the algorithm was optimized to also handle singlepol radar data.

The applied radar quantities are for the dualpol case: $Z_{H}$, $Z_{\mathrm{DR}}$, and $\rho_{\mathrm{HV}}$, and for singlepol operation just $Z_{H}$. The benefit of dualpol is that it quantifies the hydrometeor classification in relation to the correlation between $Z_{\mathrm{DR}}$ (e.g., the shape of the hydrometeors) and $\rho_{\mathrm{HV}}$ (e.g., the similarity of the particles inside the pulse volume; Straka et al. 2000). At this stage the fact that the calculation of $K_{\mathrm{DP}}$ is ambiguous due to the various estimation procedures, suggests that further investigation is required (cf. Brandes et al. 2001). Thus, despite $K_{\mathrm{DP}}$ being a typical quantity for application in a hydrometeor classification (Park et al. 2009; Al-Sakka et al. 2013; Thompson et al. 2014; Besic et al. 2016), the search for a suitable estimation of $K_{\mathrm{DP}}$ to improve the presented hydrometeor classification continues. Because of this, the focus is laid on the utilization of $Z_{H}, Z_{\mathrm{DR}}$, and $\rho_{\mathrm{HV}}$. In addition, NWP model data, namely $h_{\text {snowline }}$ (Table 1$)$, is applied to optimize the differentiation between snow and rain. The reason for this is that radar data alone is not sufficient due to the similarities in the radar signatures of the two hydrometeor types (e.g., Höller et al. 1994). Since the radar measurement heights are variable, see Fig. 2, the height was taken into account for the application of the snow line data using

$$
\Delta h_{\text {snowline }}=h_{\text {radar_beam }}-h_{\text {snowline }},
$$

where $h_{\text {radar_beam }}$ is the height of the radar measurement and $h_{\text {snowline }}$ is in meters MSL. For this purpose the snow line data 


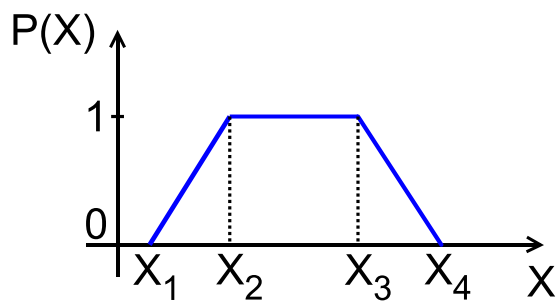

FIG. 5. Shape of the trapezoidal MBF applied in the fuzzy logic for HymecRS (section 3).

was converted from the COSMO-D2 model grid to the radar polar grid using a nearest neighbor approach. Because singlepol radar systems only provide $Z_{H}$, the application of NWP model information is necessary to create a basic hydrometeor classification.

HymecRS applies a fuzzy logic core (e.g., Liu and Chandrasekar 2000; Park et al. 2009), with trapezoidal MBF, Fig. 5. In contrast to Park et al. (2009), the radar data are assumed free of errors and nonmeteorological echoes, as it is passed through a quality assurance scheme (Werner 2014) beforehand. This scheme continuously monitors the radar system (e.g., monitoring of system offsets and drifts) and applies several interconnected modules to check the data itself (e.g., detection of spokes and rings, but also clutter detection and attenuation correction). Instead of a distinct algorithm for the separation of liquid and solid precipitation (e.g., MLDA in Park et al. 2009), HymecRS applies the NWP model snow line height.

The MBF are configured with settings of Table 2 (singlepol input) and with the characteristics in Table 3 if the complete dataset of a dualpol weather radar system is available. Park et al. (2009) also introduced two-parameter MBF [Eq. (1)], which were successfully tested and retained in HymecRS. This MBF describes the dependence of $Z_{\mathrm{DR}}$ from $Z_{H}$ and is utilized for hydrometeor classes with relation to higher $Z_{H}$ values, namely rain, big drops, graupel, and dry or wet hail, see Table 3. This underlines the impact of $Z_{\mathrm{DR}}$ for the performance of the hydrometeor classification, when particles which deviate from a spherical shape are involved (cf. Park et al. 2009).

Furthermore, for each hydrometeor class the weighted probability $A_{\text {class }}$ is calculated by

$$
A_{\text {class }}=\frac{\sum_{j=1}^{j_{\max }} W_{\text {class }, j} P_{\text {class }}\left(V_{j}\right)}{\sum_{j=1}^{j_{\max }} W_{\text {class }, j}},
$$

where $P_{\text {class }}\left(V_{j}\right)$ is the MBF value and $W_{\text {class }, j}$ is the weight of the $j$ th input quantity (e.g., radar quantities or snow line quantity) for the designated class type. The number of applied parameters $j_{\text {max }}$ concerns the different settings of the MBF for the singlepol and dualpol cases. The weights $W$ of $\Delta h_{\text {snowline }}$ are higher than those for the radar data, due to the character of the fuzzy logic as the intensification of a desired behavior is incorporated by the increase of the respective weight.
TABLE 2. Membership function setup of hydrometeor classification for singlepol radar systems.

\begin{tabular}{lccccc}
\hline \hline Input quantity & & Drizzle & Rain & Snow & Hail \\
\hline$Z_{H}(\mathrm{~dB} Z)$ & $X_{1}$ & 5 & 13 & 5 & 55 \\
& $X_{2}$ & 10 & 18 & 10 & 60 \\
& $X_{3}$ & 13 & 55.5 & 40 & 75 \\
& $X_{4}$ & 18 & 60 & 50 & 80 \\
& $W$ & 1 & 1 & 0.6 & 1 \\
$\Delta h_{\text {snowline }}(\mathrm{m})$ & $X_{1}$ & $-\infty$ & $-\infty$ & -100 & - \\
& $X_{2}$ & $-\infty$ & $-\infty$ & 0 & - \\
& $X_{3}$ & 50 & 50 & $\infty$ & - \\
& $X_{4}$ & 51.5 & 51.5 & $\infty$ & - \\
& $W$ & 2 & 2 & 2 & 0 \\
\hline
\end{tabular}

In the next fuzzy logic step, the information has to be aggregated to get the target class. The maximum value of $A_{\text {class }}$ is searched for. A detection threshold has been introduced to suppress target classes with low detection rates. The implemented values are

$$
\begin{gathered}
A_{\text {target_class,singlepol }}>0.25, \\
A_{\text {target_class,dualpol }}>0.35,
\end{gathered}
$$

and the target class unknown type is set if the relation is not fulfilled.

In the last step, a further adaptation is applied to the classification result. Thus, all signatures related to the dry hail class are reassigned to a large dry hail class, if the following condition:

$$
\rho_{\mathrm{HV}}(\text { large dry hail })<0.775
$$

is passed. This threshold was estimated by the analysis of severe reports with confirmed cases of hail, including individual hailstones with a diameter of at least $5 \mathrm{~cm}$. This separation was put into the postprocessing to suppress a bias in the performance of the hydrometeor classification in the other classes. This splitting is under evaluation and so it is not mentioned in the following processing step regarding the estimation of the surface precipitation type. The results of HymecRS from the individual radar systems are combined in a national composite.

\section{HymecNG}

The HymecRS composite is a 2D grid product with a grid spacing of $1 \mathrm{~km} \times 1 \mathrm{~km}$, covering the complete German radar network, see Fig. 1. This resolution is also deployed for HymecNG to provide an extrapolation of the hydrometeor classes to a height of $2 \mathrm{~m}$ AGL. Hence, the input data, including the irregularly distributed WS messages and the $2.2 \mathrm{~km} \times 2.2 \mathrm{~km}$ spaced NWP model vertical profiles, have to be consolidated to this grid. Unfortunately, each data source delivers the data in a different temporal resolution, which leads to temporal offsets, because there is no temporal interpolation. This means that, although the estimated precipitation type is provided with a 5-min refresh cycle of the 
TABLE 3. Membership function setup of hydrometeor classification for dualpol radar systems with utilization of two-parameter functions $f_{1}, f_{2}$, and $f_{3}$, see Eqs. (1a)-(1c).

\begin{tabular}{|c|c|c|c|c|c|c|c|c|c|c|}
\hline Input quantity & & Drizzle & Rain & Big drops & Wet snow & Dry snow & Ice crystals & Graupel & Wet hail & Dry hail \\
\hline \multirow[t]{5}{*}{$Z_{H}(\mathrm{dBZ})$} & $X_{1}$ & 5 & 13 & 27 & 25 & 5 & 0 & 25 & 45 & 47.5 \\
\hline & $X_{2}$ & 10 & 18 & 32 & 30 & 10 & 5 & 35 & 50 & 52.5 \\
\hline & $X_{3}$ & 13 & 55.5 & 45 & 40 & 35 & 20 & 50 & 65 & 75 \\
\hline & $X_{4}$ & 18 & 60 & 50 & 50 & 40 & 25 & 55 & 70 & 80 \\
\hline & $W$ & 2 & 2 & 1.8 & 1.6 & 2 & 2 & 1.8 & 2 & 2 \\
\hline \multirow[t]{5}{*}{$Z_{\mathrm{DR}}(\mathrm{dB} Z)$} & $X_{1}$ & -0.8 & $f_{1}-0.3$ & $f_{2}-0.3$ & 0.5 & -0.3 & 0.1 & -0.3 & 0.7 & -0.3 \\
\hline & $X_{2}$ & -0.5 & $f_{1}$ & $f_{2}$ & 1 & 0 & 0.4 & 0 & 1 & 0 \\
\hline & $X_{3}$ & 0.8 & $f_{2}$ & $f_{3}$ & 2 & 0.3 & 3 & $f_{1}$ & $f_{1}+2$ & $f_{1}$ \\
\hline & $X_{4}$ & 1.3 & $f_{2}+0.5$ & $f_{3}+1$ & 3 & 0.6 & 3.3 & $f_{1}+0.3$ & $f_{1}+2.5$ & $f_{1}+0.5$ \\
\hline & $W$ & 0.8 & 0.8 & 1 & 0.8 & 0.8 & 0.6 & 1.0 & 0.8 & 0.8 \\
\hline \multirow[t]{5}{*}{$\rho_{\mathrm{HV}}$} & $X_{1}$ & 0.95 & 0.92 & 0.92 & 0.88 & 0.95 & 0.95 & 0.9 & 0.82 & 0.7 \\
\hline & $X_{2}$ & 0.97 & 0.95 & 0.95 & 0.92 & 0.98 & 0.98 & 0.97 & 0.85 & 0.73 \\
\hline & $X_{3}$ & 1 & 1 & 1 & 0.95 & 1 & 1 & 1 & 1 & 1 \\
\hline & $X_{4}$ & 1 & 1 & 1 & 0.985 & 1 & 1 & 1 & 1 & 1 \\
\hline & $W$ & 0.6 & 0.6 & 0.6 & 1 & 0.6 & 0.4 & 0.4 & 0.8 & 0.8 \\
\hline \multirow[t]{5}{*}{$\Delta h_{\text {snowline }}(\mathrm{m})$} & $X_{1}$ & $-\infty$ & $-\infty$ & - & -100 & 250 & 250 & - & - & - \\
\hline & $X_{2}$ & $-\infty$ & $-\infty$ & - & 0 & 350 & 350 & - & - & - \\
\hline & $X_{3}$ & 50 & 50 & - & $\infty$ & $\infty$ & $\infty$ & - & - & - \\
\hline & $X_{4}$ & 51.5 & 51.5 & - & $\infty$ & $\infty$ & $\infty$ & - & - & - \\
\hline & $W$ & 3 & 3 & 0 & 3 & 3 & 3 & 0 & 0 & 0 \\
\hline
\end{tabular}

radar measurements, the temporal offset is at most $30 \mathrm{~min}$ for the additional data. Here, the NWP model output produces the upper temporal limit, as the WS data has a 1015-min resolution.

\section{a. Preprocessing of WS measurements}

To consolidate the irregularly distributed point measurements to uniform grid data, a spatial interpolation is advisable. For this, techniques such as inverse distance weighting (IDW) or more complex geostatistical methods like kriging, and variations of those, are widely used to estimate data at locations where no direct information is available (Babak and Deutsch 2009). The main difference between the two types is the need to know the variogram of the particular quantity for the kriging case. This leads to accurate results, but increased resources due to additional submatrix processing. Because of the last point, the IDW method was used subject to temporal restrictions of the $24 / 7$ operational environment. The IDW is characterized by

$$
T_{\mathrm{POI}}=\sum_{i=1}^{n} \lambda_{i} T_{\mathrm{WS}, i}
$$

and so, for each grid point of interest (POI), the temperatures ( $T$ in K) of $n$ WS in the neighborhood are weighted and summed up. The neighborhood is limited by a circle with a radius of $50 \mathrm{~km}$ to achieve a complete coverage of Germany, if all of the envisaged WS are available (Fig. 3). The term $T_{\mathrm{WS}, i}$ is the temperature of the $i$ th WS. The applied weight $\lambda_{i}$ is defined with

$$
\lambda_{i}=\frac{\frac{1}{d_{i}^{2}}}{\sum_{i=1}^{n}\left(\frac{1}{d_{i}^{2}}\right)},
$$

and decreases with the squared distance $d_{i}^{2}\left(\mathrm{~km}^{2}\right)$ between the WS and the POI.

The IDW is used to bring the temperatures from the WS to the grid. So far, this method only takes into account the different distances between the WS and the grid points but ignores the changing orography. Having variations in orography across Germany ranging from $-3.54 \mathrm{~m}$ MSL in the Wilstermarsch-Region in Schleswig-Holstein to $2962 \mathrm{~m} \mathrm{MSL}$ for the Zugspitze in the Alps, this must be addressed. Therefore, the temperature lapse rate of the generic standard atmosphere $\left(-6.5^{\circ} \mathrm{C} \mathrm{km}^{-1}\right.$ from American Meteorological Society (2020b), transformed to the Kelvin scale $-6.5 \mathrm{~K} \mathrm{~km}^{-1}$ ) is used. The lapse rate is added using

$$
T_{\mathrm{POI}}=\sum_{i=1}^{n} \lambda_{i}\left(T_{\mathrm{wS}, i}-6.5 \mathrm{~K} \mathrm{~km}^{-1} \Delta h_{i}\right),
$$

where $T_{\mathrm{WS}, i}$ is the measured temperature of the $i$ th WS (K), $\Delta h_{i}$ is the height difference between the $i$ th WS and the POI $(\mathrm{km})\left(\Delta h_{i}=h_{\mathrm{POI}}-h_{\mathrm{WS}, i}\right)$, and $T_{\mathrm{POI}}$ is the height adjusted temperature at the POI $(\mathrm{K})$. Now this method will take into account the different distances between the WS and the grid point as well as the height differences. Currently, the seasonal variation of the temperature height relationship (see Rolland 2003; Fan and Van den Dool 2008), is not included in the method.

Our extrapolation method (see section $4 c$ ) needs the wetbulb temperature $T_{w}(\mathrm{~K})$ (American Meteorological Society 2020c). The wet-bulb temperature $T_{w}$ is a temperature that combines the humidity with (dry-bulb) temperature and pressure measurements. Because $T_{w}$ is not directly provided by the WS, it has to be estimated. The applied derivation of $T_{w}$ follows the formulation given in Deutscher Wetterdienst (1998). Finally, the aforementioned spatial interpolation of the point message data is performed on $T_{w}$, resulting in a gridded temperature product at the height of $2 \mathrm{~m}$ AGL. 


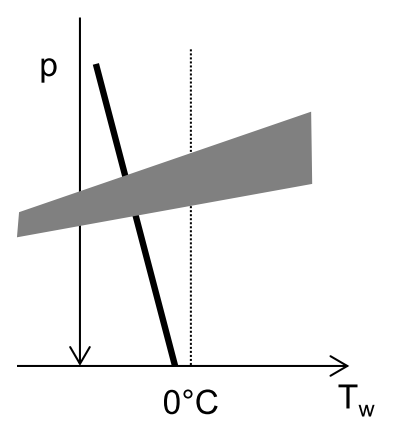

a)

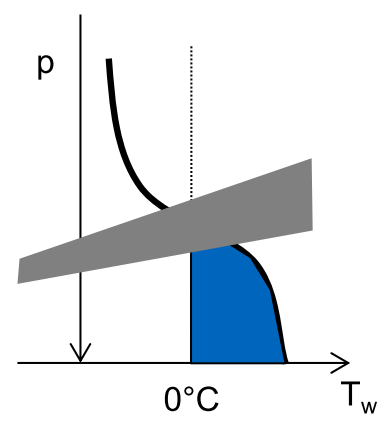

b)

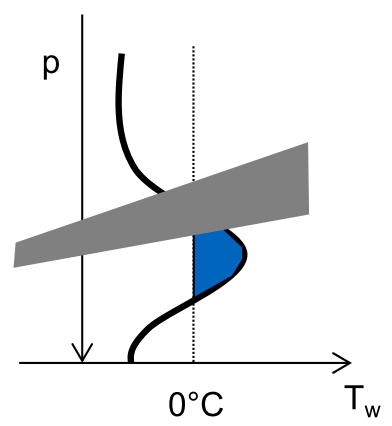

c)

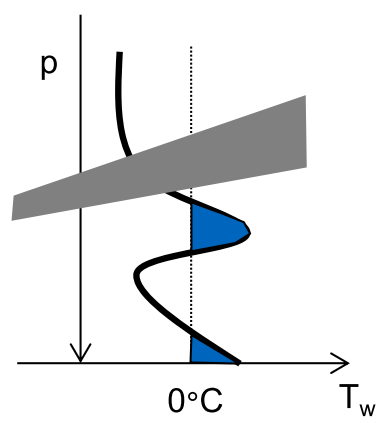

d)

FIG. 6. Sketch of four example constellations of temperature vertical profiles with the utilized melting area in blue and the radar ray in dark gray. The profiles differ in the number of intersections with $T_{w}=273.15 \mathrm{~K}\left(0^{\circ} \mathrm{C}\right)$ : (a) 0 , (b) 1 , (c) 2 , and (d) 3 .

\section{b. Adaptation of NWP with ground measurements}

As discussed in the preceding section, $T_{w}$ is the quantity of choice for the envisaged processing. Unfortunately, this parameter is not provided directly as a vertical profile, and so it has to be estimated from $T, q$, and $p$, see Table 1 . To do so, a postprocessing method of the COSMO-D2 model was used. Then, the vertical profiles of $T_{w}$ are converted from the $2.2-\mathrm{km}$ model grid to the 1-km target grid using a nearest neighbor approach. This means, each NWP vertical profile influences at least four target grid cells. After that, the digital elevation model (DEM) of the target grid is applied to include an appropriate lower limit of the profiles. At this stage, the profiles are cut or extrapolated at the bottom using a linear fit to the relevant lowest data layers.

Inaccuracies in the forecasted meteorological quantities need to be reduced, at least in the lower boundary layer. For this, the combination with the spatially interpolated WS measurements is applied [Eq. (8)]. At first, the grid product of the near surface wet-bulb temperature of the WS $T_{w \text {,ws }}$, is taken as ground truth. The values of $T_{w, \mathrm{ws}}$ are utilized as follows: they are taken at the height of $2 \mathrm{~m}$ AGL exclusively with decreasing weight for heights above. The idea behind this method is to trust the WS data near the surface but to keep the trend of the vertical profiles that are provided by the NWP model. Hence, the measurements shall not suppress model output regarding the vertical variations of the meteorological conditions. The implemented relationship is derived using

$$
T_{w}(h)=\frac{h}{h_{\max }} T_{w, \mathrm{NWP}}(h)+\left(1-\frac{h}{h_{\mathrm{max}}}\right) T_{w, \mathrm{WS}},
$$

with $T_{w}(\mathrm{~K})$ and is executed for heights $h$ between $2 \mathrm{~m}$ AGL and $h_{\max }=500 \mathrm{~m}$ AGL. This kind of adaptation is comparable to the method in Scheuerer et al. (2017) with differences in the applied ground truth and in the value of $h_{\max }$. Scheuerer et al. (2017) applied a much higher limit with $h_{\max } \approx 5500 \mathrm{~m}(p=$ $500 \mathrm{hPa}$ ). This strong variation may be due to the diverse analysis of the vertical profiles, as described in section 4c.

\section{c. The extrapolation method}

The application of vertical temperature profiles for estimating precipitation type is tackled in various ways. For example, Reeves et al. (2016) or Scheuerer et al. (2017) solely concentrated on the vertical profiles of $T_{w}$ and proved the applicability of such a data source. In contrast to this, Schuur et al. (2014) combined the temperature profiles with results of a hydrometeor classification based on weather radar data. The common topic of these publications is a focus on winter precipitation types. However, due to the envisaged implementation in an operational environment the algorithm HymecNG was set up to perform on summer and winter season cases in equal measure.

The main idea is that the result of the hydrometeor classification at the radar beam height (see section 3 ) is checked for melting along the path to the surface. Hence, this addresses the hydrometeor classes that are most vulnerable to this kind of phase change: the complete or partly frozen types of wet snow, dry snow, and ice crystals. The chosen quantity representing the melting process is the so-called melting area $A_{\text {melt }}(\mathrm{K} \mathrm{hPa})$. The corresponding definition is

$$
A_{\text {melt }}=\Delta T_{w} \Delta p
$$

utilizing $\Delta T_{w}$ the difference in the vertical profile of the wetbulb temperature $(\mathrm{K})$ and $\Delta p$ the difference of the pressure $p(\mathrm{hPa})$ as a height dependent quantity. The adapted vertical profiles presented in section $4 \mathrm{~b}$ are employed with the condition $T_{w}>273.15 \mathrm{~K}\left(0^{\circ} \mathrm{C}\right)$ and at the corresponding height of the applied weather radar based hydrometeor class. Figure 6 presents four typical vertical profiles with the designated melting area marked in blue and the radar ray in dark gray. The empirically estimated melting areas for reproducing the melting process are summarized in Fig. 7 together with the applied $Z_{H}$ thresholds for separating the liquid precipitation types. Further remarks on the estimation of the precipitation type are as follows.

Due to missing studies, the three hail classes are recombined to one hail type. Then, precipitation with unknown type or hail is integrated directly in HymecNG without any adaption. Wet snow can be transformed to the whole liquid type with $A_{\text {melt }}>$ $15 \mathrm{~K} \mathrm{hPa}$, or still reside in the frozen-liquid-mixture (rain and snow) type. The transition of the frozen classes dry snow, ice crystals and graupel, is determined by the use of $A_{\text {melt }}$ in the three types: liquid, $A_{\text {melt }}>20 \mathrm{~K} \mathrm{hPa}$, frozen-liquid-mixture, $10 \mathrm{~K} \mathrm{hPa}<A_{\text {melt }} \leq 20 \mathrm{~K} \mathrm{hPa}$, and frozen, $A_{\text {melt }} \leq 10 \mathrm{~K} \mathrm{hPa}$. 


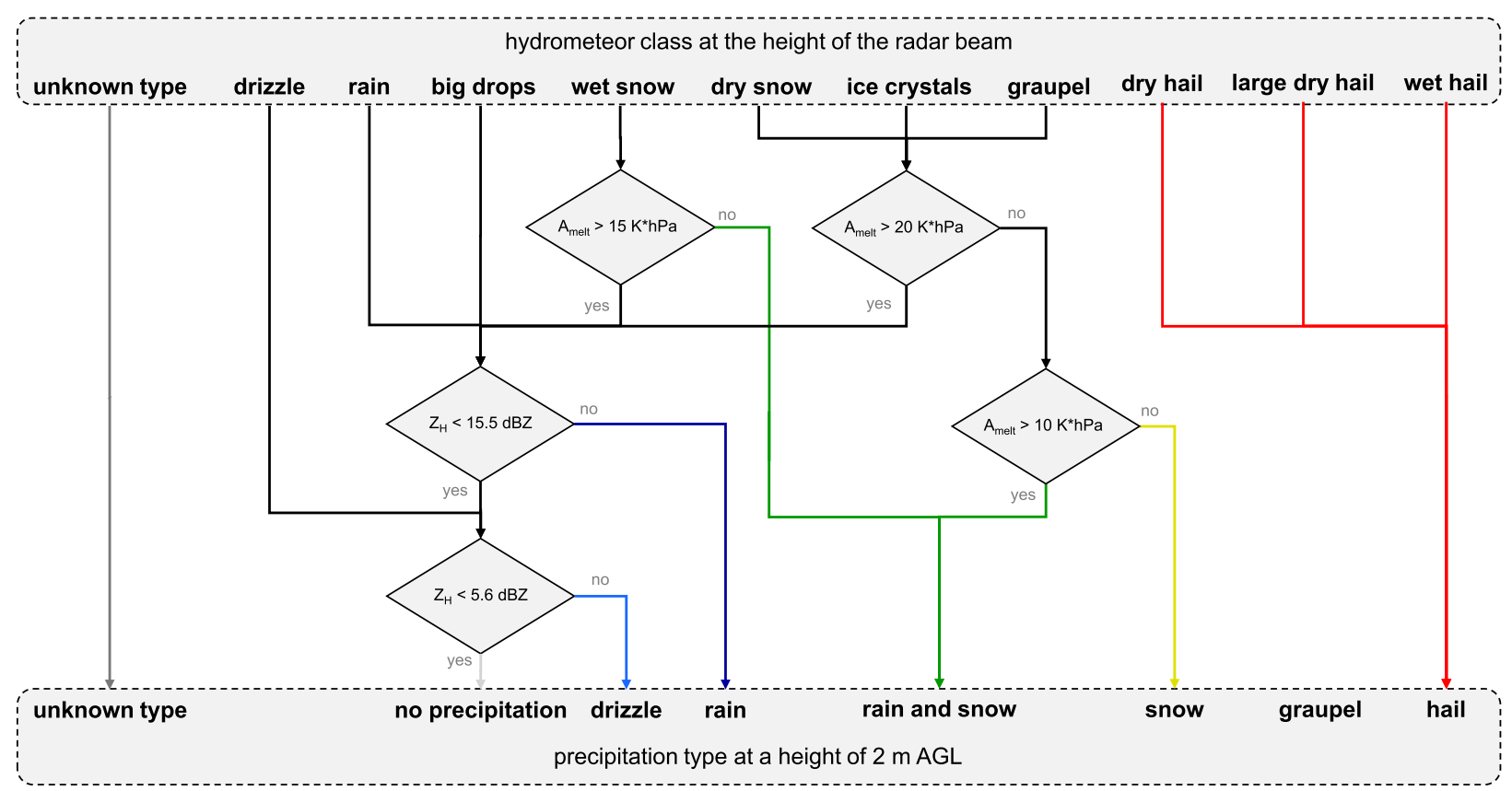

FIG. 7. Flowchart of the HymecNG algorithm to estimate the precipitation type at a height of $2 \mathrm{~m}$ AGL from the hydrometeor class at the radar beam height. Displayed are the applied values of the melting area $A_{\text {melt }}$ and the radar beam reflectivity $Z_{H}$.

Every $A_{\text {melt }}$ threshold was empirically estimated within the HymecNG evaluation process. For this, reports of the weather code from selected weather stations and human observers were used as reference.

In addition, the designated liquid particles are tested for passing two reflectivity thresholds. For this, the untreated reflectivity from the height of the radar measurement is applied. A value of $Z_{H}=15.5 \mathrm{dBZ}$ is chosen for the splitting into rain and potentially drizzle. Thereby, this threshold is the simple mean of the values utilized in the MBF of the hydrometeor classification (see Table 3 ) for drizzle and rain. The designated drizzle signatures are then checked for the passing of the $Z_{H}=5.6 \mathrm{dBZ}$ threshold to separate the no precipitation type. This threshold is based on the application of the DWD standard $Z-R$ relationship: $Z_{H}=256 R^{1.42}$, with $Z_{H}=10 \log _{10}\left(Z_{H}\right)$ and $R$ the rain rate $\left(\mathrm{mm} \mathrm{h}^{-1}\right)$. As an appropriate lower rain rate threshold, a value of $R=0.05 \mathrm{~mm} \mathrm{~h}^{-1}$ is chosen, which is at least below the upper threshold of the minimal drizzle class $\left(0.1 \mathrm{~mm} \mathrm{~h}^{-1}\right.$, Deutscher Wetterdienst 2018).

The graupel case leads to a dilemma, since with the implemented settings (Table 3) it may be associated with soft hail or snow pellets at the top of the melting zone, as mentioned in American Meteorological Society (2020a). This correspondence to snow pellets may result in circular segment structures around the weather radar sites, see section $4 \mathrm{~d}$. At this stage, no appropriate setting was found for handling this effect in the extrapolation procedure along the path to the surface. Because of this, the decision was made to handle the hydrometeor graupel class exactly as the dry snow class. This is a topic for the summer season, within which the graupel classifications give valid results for the soft hail type. Furthermore, in such events snow pellets are no problem, due to the typically higher temperature values. In addition, the restriction of HymecNG to solid, mixed, and liquid type precipitation addresses the most urgent needs at the DWD sufficiently.

\section{d. Case studies}

To get an impression of the hydrometeor classification results, two case studies, one in the winter and the other in the summer, were extracted from the operational processing. Both cases contain composite data from the German weather radar network, see Fig. 1. The winter season case was recorded at 0000 UTC 4 February 2020 and is arranged in Fig. 8. For this event with stratiform precipitation, the result of HymecRS (Fig. 8d) is characterized by a height-related transition from dry snow across wet snow to rain. By looking at $h_{\text {snowline }}$ (Fig. 8a) in combination with the measurement height, the difference $\Delta h_{\text {snowline }}$ [Eq. (2)] can be reconstructed to identify the melting regions, see the wet snow class in Fig. 8d. In addition, the increased $Z_{H}$ values yield ring segments around the radar site locations, see Fig. $8 \mathrm{~b}$, that confirm the presence of a melting region. The summer season case is displayed in Fig. 9 and describes the situation at 1700 UTC 13 June 2020. For this convective event, the HymecRS product (Fig. 9d) shows some spots with hail signatures and the hail classifications correlate with peaks in $Z_{H}$ in this event (Fig. 9b). While, this is no quantitative validation, it shows at least that the method produces reasonable results, as confirmed within the evaluation process.

Example results of the IDW interpolated $T_{w}$ are displayed in Fig. $8 \mathrm{c}$ for the previously mentioned winter season case and in Fig. $9 \mathrm{c}$ for the summer season case. Apart from the large seasonal difference in the temperature values, the case studies have certain similarities. The heights of the single grid points 

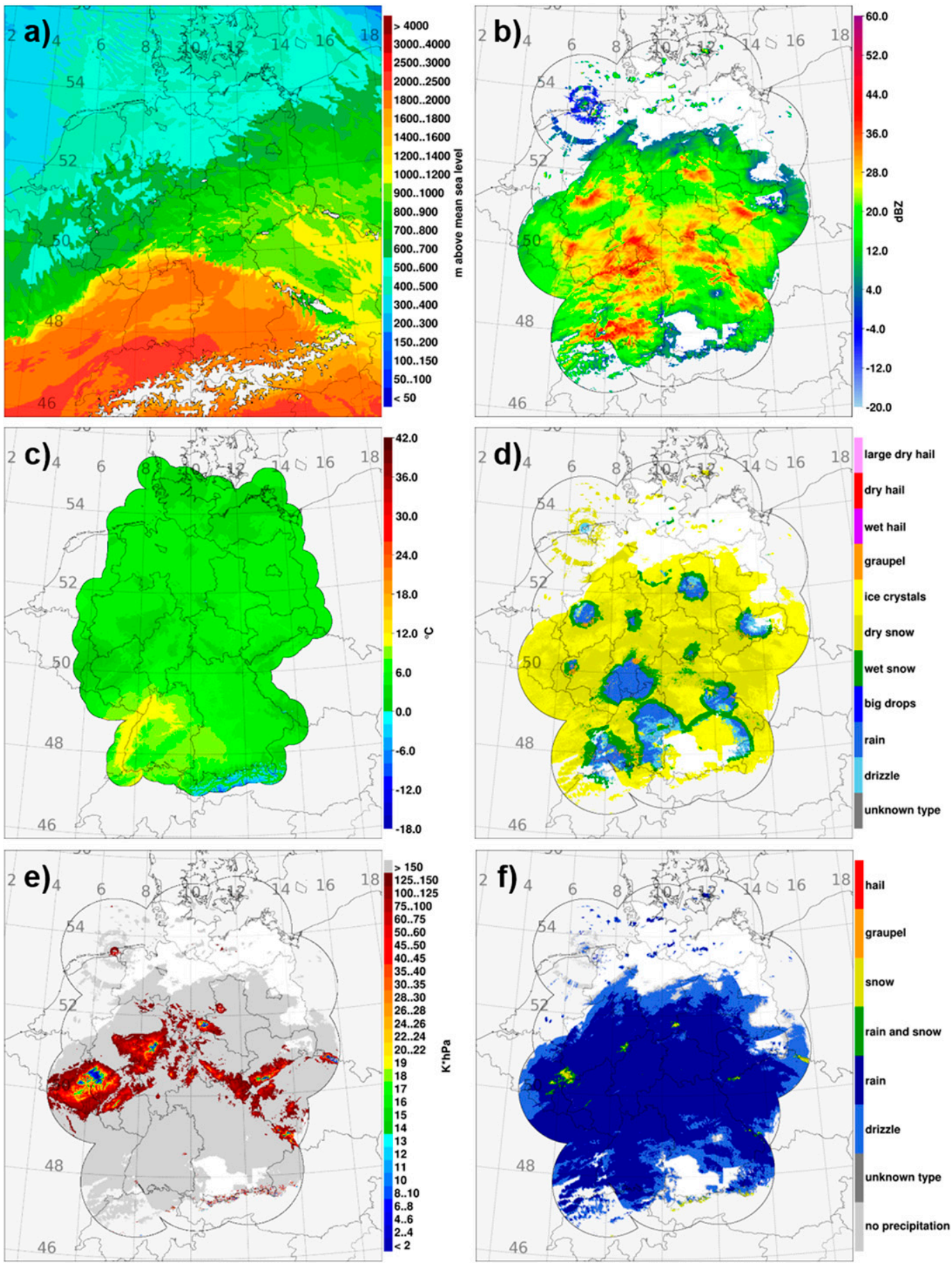

FIG. 8. Winter season case study valid at 0000 UTC 4 Feb 2020. (a) COSMO-D2 $h_{\text {snowline }}(\mathrm{m}$ MSL), (b) composite of $Z_{H}(\mathrm{dBZ})$, (c) areal interpolated $T_{w}$ at a height of $2 \mathrm{~m}$ AGL based on WS data, (d) HymecRS result valid for the radar beam height, (e) available $A_{\text {melt }}(\mathrm{K} \mathrm{hPa})$, and (f) HymecNG result for precipitation type at a height of $2 \mathrm{~m}$ AGL. (Environmental data: (C) GeoBasis-DE/BKG $<2015>$ ).

reveal lower temperatures in mountainous regions due to the lapse rate and the outline of the coverage consists of circle segments with the applied 50-km radius. In regions where $T_{w}$ information is unavailable from the interpolated WS data,
NWP model $T_{w}$ is used to provide a completely filled product for further processing. The treatment is done on a pixel by pixel basis from either the WS or the NWP model without interference between them. 

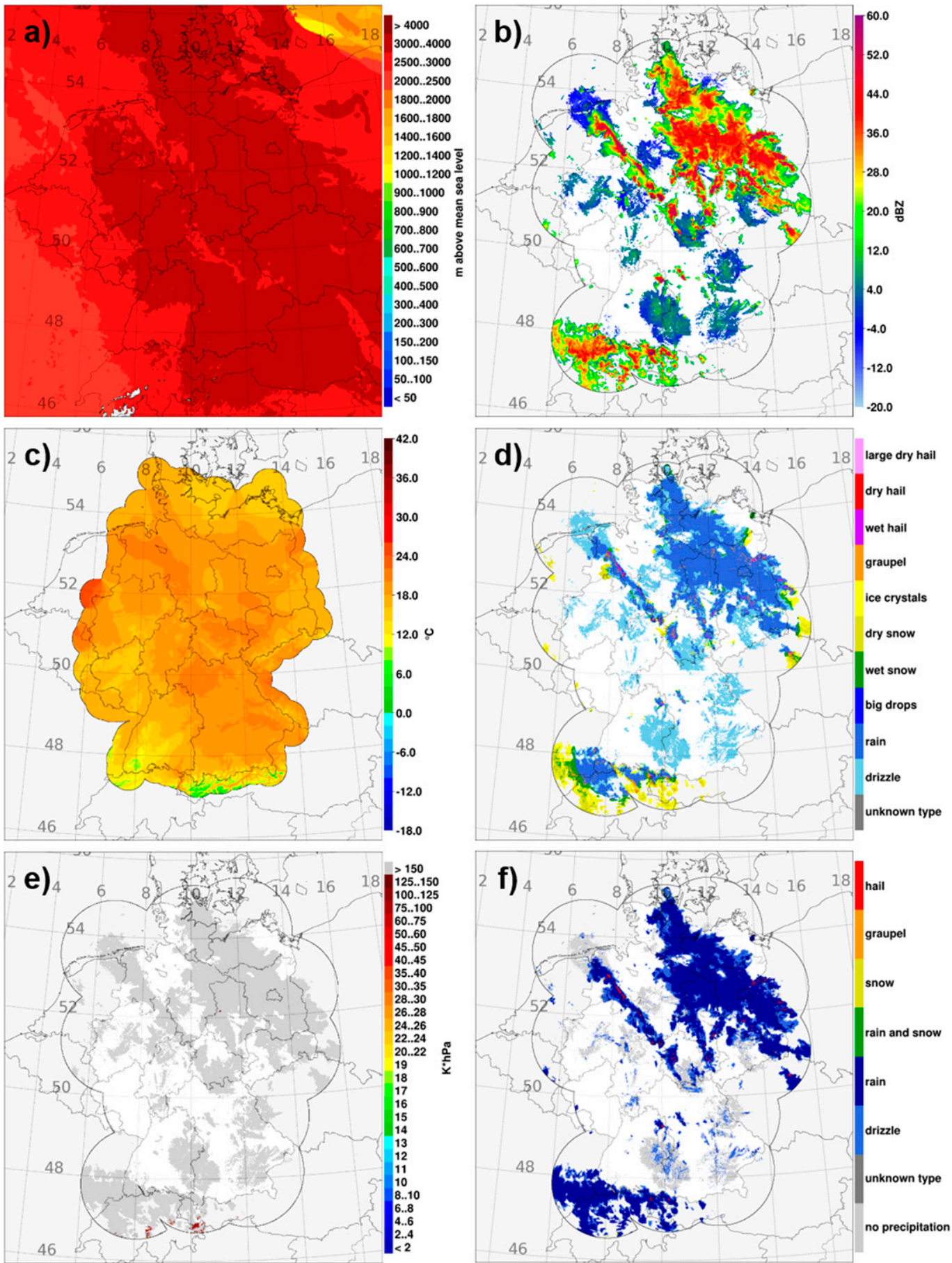

FIG. 9. Summer season case study valid at 1700 UTC 13 Jun 2020. (a) COSMO-D2 $h_{\text {snowline }}$ (m MSL), (b) composite of $Z_{H}(\mathrm{dBZ})$, (c) areal interpolated $T_{w}$ at a height of $2 \mathrm{~m}$ AGL based on WS data, (d) HymecRS result valid for the radar beam height, (e) available $A_{\text {melt }}(\mathrm{K} \mathrm{hPa})$, and (f) HymecNG result for precipitation type at a height of $2 \mathrm{~m}$ AGL. (Environmental data: (c) GeoBasis-DE/BKG $<2015>$ ).

The examples for winter (Fig. 8) and summer (Fig. 9) also include associated results for melting area and precipitation type at a height of $2 \mathrm{~m}$ AGL. Starting with the melting area, the summer season case has fewer regions with relevant values for the melting transition zone (cf. Fig. 9e with Fig. 8e) due to higher temperature values in the vertical profiles. For example, values $>150 \mathrm{~K} \mathrm{hPa}$ are colored gray in the plots to focus on the crucial values for the melting process. Further, the estimated 
TABLE 4. Assignment of disdrometer (LPM), HymecRS and HymecNG precipitation types to aggregated classes for verification. NoEcho type stands for no (meteorological) echoes in the radar measurements.

\begin{tabular}{|c|c|c|c|c|}
\hline LPM class & Description & HymecRS class & HymecNG class & Verification class (phase) \\
\hline NP & No precipitation & NoEcho & No precipitation; NoEcho & No precipitation \\
\hline UP & Unknown precipitation & Unknown type & Unknown type & - \\
\hline $\mathrm{DZ}$ & Drizzle & Drizzle & Drizzle & Liquid \\
\hline RADZ & Drizzle and rain mixture & - & - & Liquid \\
\hline RA & Rain & Big drops; rain & Rain & Liquid \\
\hline RASN & Snow and rain mixture & Wet snow & Rain and snow & Mixed \\
\hline SN & Snow & Dry snow & Snow & Solid \\
\hline SG & Snow grains & Ice crystals & Snow & Solid \\
\hline GS & Snow pellets or soft hail & Graupel & Graupel & Solid \\
\hline GR & Hail & Wet hail; dry hail; large dry hail & Hail & Solid \\
\hline
\end{tabular}

precipitation type in the winter season case (Fig. 8f) demonstrates the application of $A_{\text {melt }}$ with large territories of liquid precipitation, which was derived from any hydrometeor class except for the hail types, see Fig. 8d. Nevertheless, there are elevated mountainous areas with snowfall and zones of mixed rain and snow at lower altitudes. The summer season case paints another picture (Fig. 9f) as there are hail signatures outside of the Alps that show some melting. In addition, this case reveals the importance of the year-round character of HymecNG, since convective cells on low-lying plains are able to coexist with melting-related precipitation in high mountain regions.

\section{Verification}

The key factor for enabling a meaningful verification is the significance of the reference data (ground truth). In this sense, a suitable temporal and spatial allocation of the estimated Hymec data to the reference data must be given. The applied height of $2 \mathrm{~m}$ AGL for HymecNG is beneficial, given the widespread availability of instruments measuring at this height. At first glance, the sensors of the addressed WS (see section 2c) are a possible ground truth. The difficulty at this stage is that the temperature measurements of the WS are already used for both the precipitation type estimation of the WS and the HymecNG algorithm. As a result, the WS must be ruled out as ground truth to maintain result independence. So, the output from LPM (see section 2d) was chosen.

\section{a. Verification database}

The set of acceptable precipitation types is a point of discussion as it differs between the LPM, HymecRS, and HymecNG results. In consequence, the implemented strategy follows Bloemink and Lanzinger (2005) and consolidates the data source outputs to the types: no precipitation and precipitation in liquid, mixed, or solid phase, see Table 4.

The applied dataset covers the 322-day period from 25 March 2020 to 9 February 2021. The temporal resolution of the disdrometer data was adapted to the $5 \mathrm{~min}$ output frequency of Hymec. Because of this, only a fifth of the 1 min LPM messages were added to the pool of ground truth data. To sum up, a hypothetical dataset of 322 days $\times 288$ time steps per day $\times 15$ sites $\times 2$ LPMs $=2782080$ data points should be available for verification. However, due to missing data associated with maintenance work and the neglect of precipitation classified as type "unknown," the verification database reduces by a quarter to approximately 2.1 million comparative values.

\section{b. Interpretation of verification results}

HymecNG was applied to adapted NWP vertical profiles of the wet-bulb temperature associated with LPM measurements of liquid, mixed, solid, or no precipitation. NWP profiles contain errors of the numerical weather forecasts, and this dilutes the verification results for HymecNG. Nevertheless, NWP profiles are the only data with the required temporal and spatial resolution available for HymecNG in the operational environments of national weather services and therefore a preferred data source to estimate the thermodynamical profiles in the lower troposphere.

The allocation to the aforementioned four verification classes (no precipitation and precipitation in liquid, mixed or solid phase) was done for comparing LPM data with HymecRS output as well as with the HymecNG results. So a better classification of the HymecNG products can be made by looking at shifts in relation to the HymecRS verification. The counting results are summarized as contingency tables for LPM against HymecRS in Table 5 and for LPM against HymecNG in Table 6. Starting with the precipitation distribution, the LPM data show a large number of no precipitation events $(88.9 \%)$. This is a setback for the verification as the analysis of the correct precipitation type is based on only $11.1 \%$ of the available data. Another topic is the distribution of the precipitation classes. Here almost all events are related to the liquid phase. In consequence, the mixed phase is represented by only 808 cases and the solid precipitation by 39724 cases. Although this may limit the usefulness for the latter two verification classes, the precipitation distribution represents the actual weather situation.

Bloemink and Lanzinger (2005) verified the LPM data with manual observations. They showed that the LPM is very sensitive, since it can register precipitation in cases where an observer would report none. This has to be kept in mind when verifying events with or without precipitation. In addition to assessing the classification accuracy, three verification measures are estimated to score the HymecRS and HymecNG results. For the score calculation, the following four definitions 
TABLE 5. Comparison of the hydrometeor classification HymecRS output with the data of 30 LPM (ground truth), see black points in Fig. 1. The mapping of the precipitation types is summarized in Table 4. Analyzed time span: 25 Mar 2020-9 Feb 2021.

\begin{tabular}{lccccc}
\hline \hline & \multicolumn{4}{c}{ LPM } \\
\cline { 2 - 6 } \multicolumn{1}{c}{ HymecRS } & No precipitation & Liquid phase & Mixed phase & Solid phase & Total \\
\hline No precipitation & 1771144 & 48041 & 139 & 13123 & $1832447(87.4 \%)$ \\
Liquid phase & 26881 & 77610 & 2 & 47 & $104540(5.0 \%)$ \\
Mixed phase & 3689 & 10805 & 80 & 3191 & $17765(0.8 \%)$ \\
Solid phase & 62781 & 55514 & 587 & 23363 & $142245(6.8 \%)$ \\
Total & $1864495(88.9 \%)$ & $191970(9.2 \%)$ & $808(<0.1 \%)$ & $39724(1.9 \%)$ & $2096997(100 \%)$ \\
POD & 0.95 & 0.40 & 0.10 & 0.59 & 0.84 \\
FAR & 0.03 & 0.26 & 1.00 & 0.23 & \\
HSS & 0.65 & 0.49 & 0.01 & & \\
Overall accuracy & & & $89.3 \%$ & &
\end{tabular}

are required with regards to a particular precipitation phase based on Bloemink and Lanzinger (2005):

- TP (true positives): the LPM reports the precipitation phase and Hymec classifies the same precipitation phase

- FP (false positives): Hymec classifies the phase, but the LPM reports another precipitation phase or no precipitation

- FN (false negatives): the LPM reports the particular phase, but Hymec classifies another precipitation phase or no precipitation

- TN (true negatives): the LPM does not report the phase and Hymec also does not classify the phase

The three implemented scores are then the probability of detection (POD):

$$
\mathrm{POD}=\frac{\mathrm{TP}}{\mathrm{TP}+\mathrm{FN}},
$$

the false alarm ratio (FAR):

$$
\mathrm{FAR}=\frac{\mathrm{FP}}{\mathrm{TP}+\mathrm{FP}},
$$

and the Heidke skill score (HSS):

$$
\mathrm{HSS}=\frac{2(\mathrm{TP} \times \mathrm{TN}-\mathrm{FN} \times \mathrm{FP})}{(\mathrm{TP}+\mathrm{FP})(\mathrm{FP}+\mathrm{TN})+(\mathrm{TP}+\mathrm{FN})(\mathrm{FN}+\mathrm{TN})} .
$$

The values of POD ranges from 0 (no detection) to 1 (100\% recognition) and for FAR from the best value 0 (no false alarms) to 1 (every recognition is wrong). The minimum value for HSS is $-\infty$ (worst result) and the upper limit is 1 (perfect detection). The HSS is a relative measure to the random guess. So, 0 stands for no skill, which means the estimation equals a random guess. The skill increases until HSS reaches 1 .

The presented methods deliver a very good detection for the no precipitation case, see Tables 5 and 6 . The POD is around 0.96 and FAR is low with 0.04 for HymecRS and HymecNG. The HSS is not perfect, but with approximately 0.7 , it is far better than a random guess. The HymecNG algorithm performs slightly better, which can be linked to the additional class for no precipitation in regions with liquid phase hydrometeors. The classification success is related to radar measurement preprocessing with regards to quality assurance. Hence, the NoEcho type was set in regions with no (meteorological) signatures and stands also for no precipitation.

The liquid precipitation phase, with the highest occurrence, gives good results in HSS that are comparable to the no precipitation case. Though the POD is now lower, it increases from HymecRS $(\mathrm{POD}=0.40)$ to HymecNG $(\mathrm{POD}=0.69)$. This is encouraging, because the implemented melting scheme leads to an improvement for the liquid precipitation phase. Better hit rates are achievable if the aforementioned excessive precipitation sensitivity of the LPM and the less-than-ideal handling of the lower threshold for precipitation can be enhanced. The high values of false alarms (HymecRS: FAR = 0.26 ; HymecNG: FAR $=0.34$ ) are a result of lacking a method for adapting the precipitation amount when extrapolating the

TABLE 6. Comparison of the estimated precipitation type HymecNG output with the data of 30 LPM (ground truth), see black points in Fig. 1. The mapping of the precipitation types is summarized in Table 4. Analyzed time span: 25 Mar 2020-9 Feb 2021.

\begin{tabular}{lccccr}
\hline \hline & \multicolumn{3}{c}{ LPM } \\
\cline { 2 - 6 } \multicolumn{1}{c}{ HymecNG } & No precipitation & Liquid phase & Mixed phase & Solid phase & Total \\
\hline No precipitation & 1787848 & 54555 & 139 & 13139 & $1855681(88.5 \%)$ \\
Liquid phase & 66494 & 132036 & 33 & 203 & $198766(9.5 \%)$ \\
Mixed phase & 1341 & 3607 & 184 & 3706 & $8838(0.4 \%)$ \\
Solid phase & 8812 & 1772 & 452 & 22676 & $33712(1.6 \%)$ \\
Total & $1864495(88.9 \%)$ & $191970(9.2 \%)$ & $808(<0.1 \%)$ & $39724(1.9 \%)$ & $2096997(100 \%)$ \\
POD & 0.96 & 0.69 & 0.23 & 0.57 & 0.33 \\
FAR & 0.04 & 0.34 & 0.98 & 0.61 & \\
HSS & 0.66 & 0.64 & & & \\
Overall accuracy & & & $92.6 \%$ & &
\end{tabular}


TABLE 7. Comparison of the precipitation type forecast COSMO-D 2 ww with the data of 30 LPM (ground truth), see black points in Fig. 1. The mapping of the precipitation types is summarized in Table 4. Analyzed time span: 25 Mar 2020-9 Feb 2021.

\begin{tabular}{|c|c|c|c|c|c|}
\hline \multirow[b]{2}{*}{ COSMO-D2 ww } & \multicolumn{5}{|c|}{ LPM } \\
\hline & No precipitation & Liquid phase & Mixed phase & Solid phase & Total \\
\hline No precipitation & 1785453 & 59589 & 139 & 10364 & $1855545(87.1 \%)$ \\
\hline Liquid phase & 97474 & 126014 & 134 & 1315 & $224937(10.6 \%)$ \\
\hline Mixed phase & 3169 & 2537 & 0 & 4 & $5710(0.3 \%)$ \\
\hline Solid phase & 9819 & 5484 & 617 & 29348 & $45268(2.1 \%)$ \\
\hline Total & $1895915(88.9 \%)$ & $193624(9.1 \%)$ & $890(<0.1 \%)$ & $41031(1.9 \%)$ & $2131460(100 \%)$ \\
\hline POD & 0.94 & 0.65 & 0.00 & 0.72 & \\
\hline FAR & 0.04 & 0.44 & 1.00 & 0.35 & \\
\hline HSS & 0.60 & 0.56 & 0.00 & 0.67 & \\
\hline Overall accuracy & \multicolumn{5}{|c|}{$91.1 \%$} \\
\hline
\end{tabular}

radar measurement height to $2 \mathrm{~m}$ AGL. The assumption is that the radar detects (low intensity) precipitation that evaporates before reaching the surface disdrometers. Another possibility is a horizontal precipitation drift and an unknown time shift between the radar measurement and the precipitation at $2 \mathrm{~m}$ AGL. The effects of both may decrease if there is widespread stratiform precipitation and increase for shower or hail events due to small-scale convective cells.

The transition from snow to rain is difficult to handle since there are only 808 cases in the verification database. Although radar measurements are a useful indicator with bright band detection (see Werner and Steinert 2012), the result is hard to verify quantitatively. Furthermore, the estimation by the LPM has a low hit rate with $\mathrm{POD}=0.25$ (Bloemink and Lanzinger 2005). As a consequence, the slight improvements from the poor values for HymecRS $(\mathrm{POD}=0.10$; FAR $=1.0$; HSS = $0.01)$ to HymecNG $(\mathrm{POD}=0.23 ; \mathrm{FAR}=0.98 ; \mathrm{HSS}=0.04)$ may be seen as a step in the right direction. As for the liquid case, the implemented melting procedure leads to a reduction of the mixed phase classification and also to a better detection. The high amount of false alarms shows a trend toward the liquid phase, which may be a hint for a future adaptation of the $A_{\text {melt }}$ configuration in the HymecNG algorithm.

Looking at the solid phase (39724 cases), again the HymecNG results $(\mathrm{POD}=0.57$ FAR $=0.33$; $\mathrm{HSS}=0.61)$ outperform the HymecRS results $(\mathrm{POD}=0.59 ; \mathrm{FAR}=0.84$; HSS $=0.24$ ) in general even though the number of solid phase classifications is reduced. HymecNG reduces the FAR remarkably. The slight decrease in the POD corresponds to an increase in mixed phase classifications. This means that the aforementioned adaption of the $A_{\text {melt }}$ configuration might fix this effect. Furthermore, the recognition of the LPM sensitivity topic can assist in reducing the high number of classifications of the no precipitation type. The many false alarms are mainly connected to the observation of no precipitation similar to the liquid precipitation case. Because of this, an improvement could be achieved by implementing a method for handling variations in precipitation amount.

The overall accuracy of HymecRS (89.3\%), although a good value, is slightly higher for HymecNG (92.6\%). However, this score relates to verification class distribution. So the good results for the no precipitation class as well as the liquid phase class mask the problems in the detection of mixed or solid phase cases.

\section{c. Comparison to COSMO-D2 precipitation type}

To confirm the achieved verification results we compare the precipitation type estimates of HymecNG and COSMO-D2. The COSMO-D2 model provides the parameter ww that represents the precipitation type (Table 1). As part of the COSMO-D2 postprocessing, forecasts for the temperature and the intensity of liquid or solid precipitation are put into a Boolean decision tree (Pflüger 2019). The results are forecasts of ww in the COSMO-D2 model domain valid for $2 \mathrm{~m}$ AGL at a 1-h resolution. For comparison to the HymecNG verification, ww is validated against the LPM data. To keep the verification setting of section 5b, the ww is adapted to the LPM as follows. The nearest neighbor COSMO-D2 grid cell is linked to the LPM position and the (1-h constant) ww is assigned to 12 (5-min) LPM messages. To get the best verification result for the COSMO-D2 algorithm the latest available model run compared to an operational setting is used for the COSMO-D2 verification (lead time $T+2 \mathrm{~h}$ to $T+4 \mathrm{~h}$ depending on the observation time of LPM messages). Furthermore, the ww precipitation code is sorted into the four verification types: no precipitation and precipitation in liquid, mixed and solid phase. The verification results are summarized in Table 7. Especially for no precipitation and the liquid phase, they are similar to the HymecNG verification (Table 6). For the solid phase, ww $(\mathrm{POD}=0.72)$ has a better performance than HymecNG $(\mathrm{POD}=0.57)$. But the precipitation in the mixed phase shows the opposite, as the skill of HymecNG $(\mathrm{POD}=0.23)$ is higher than of ww $(\mathrm{POD}=0)$. HymecNG slightly outperforms ww in the overall accuracy $(92.6 \%$ against $91.1 \%$ ). To sum up, the comarison between both methods shows comparable results. The specific handling of the melting area in HymecNG leads to a positive trend for the detection of mixed phase cases. Because of the verification results and the better temporal and spatial resolution, the observation based HymecNG precipitation type is preferred to the COSMO-D2 ww NWP output. Although the verification differences are minor, the HymecNG algorithms have the advantage of a strong focus on observations with a higher spatial and temporal resolution of the provided classification results $(1 \mathrm{~km} \times 1 \mathrm{~km}$ grid cell size with a 
5-min repetition time) than NWP output, thus allowing a faster update and spatially more precise assimilation of changes in the meteorological conditions.

\section{Conclusions}

In this paper, we introduce a new comprehensive method for estimating the precipitation type at a height of $2 \mathrm{~m}$ AGL. The implemented scheme consists of two parts: a hydrometeor classification at radar beam height (HymecRS) and an extrapolation of the hydrometeor classes to a height of $2 \mathrm{~m} \mathrm{AGL}$ (HymecNG).

In addition to dual-polarization weather radar data (C-band), the output from the regional NWP model COSMO-D2 and measurements from several types of meteorological stations were applied to get improved precipitation type information in a $1 \mathrm{~km} \times 1 \mathrm{~km}$ grid, spanning the whole coverage of DWD's weather radar network. HymecRS consists of a fuzzy-logic core that uses dual-polarization radar data, together with a 2D NWP model field of the height level with snow above and rain below. HymecNG takes the HymecRS result and applies it to adapted NWP model vertical profiles of the wet-bulb temperature. The implemented algorithm calculates the "thermodynamic melting area" from the corrected vertical profiles to indicate possible melting of solid or mixed phase hydrometeors.

A verification against disdrometer data shows an improvement in the HymecRS results using the 2-m output of HymecNG. In particular the detection of mixed phase and solid phase particles improves. In addition, liquid phase particles are well detected. A supplementary verification of COSMO-D2 precipitation type (1-h resolution) against disdrometer data proves the enhanced detection of mixed phase particles with HymecNG.

The positive outcome of several months of evaluation in an operational weather forecasting environment gave an impetus for proceeding with implementing the presented method. The algorithms were integrated in the operational framework at DWD with a 5-min and all-season schedule. In addition, the provided HymecNG precipitation type product was incorporated into the operational visualization framework NinJo (Koppert et al. 2004; Joe et al. 2005; Heizenreder and Haucke 2009) and assists the meteorologists in preparing severe weather warnings and forecast reports.

Further improvements of $\mathrm{HymecNG}$ are possible in the future. Based on our results, other available surface observations, such as quality-controlled crowd-sourced data with even higher spatial and temporal resolution (Elmore et al. 2014; Chapman et al. 2017; Meier et al. 2017), could be used together with Rapid Update Cycle NWP model data to further enhance the found improvements.

Furthermore, the verification suggests possible adaptations of the algorithm configuration settings. Possible enhancements are the tuning of the "thermodynamic melting area" thresholds for mixed phase precipitation and the implementation of an algorithm for handling sublimation and evaporation below the precipitation scan level.

Another unaddressed topic is the correct classification of graupel signatures and finding a suitable method to differentiate between soft hail and snow pellets. An extension to further precipitation types is envisaged. Candidates are ice pellets and freezing rain despite limited prospects of success (Reeves et al. 2014). Because of the lack of suitable identifications to tune HymecNG, refreezing (e.g., Reeves et al. 2016) has not been considered so far. The disregard of a potential phase change in graupel or hail classes results from first requiring a deeper analysis in this field.

Currently, adjusting the range resolution for the 10 fixed elevation scans to $250 \mathrm{~m}$ is planned. With this step, the application of these additional scans for the precipitation type estimation becomes more important. In particular information about vertical variations in the radar signatures should have some positive impact on the processing of the precipitation type. The future implementation of the improvements will be accompanied by an ongoing evaluation.

The German Weather Service plans to use HymecNG as input for the core nowcasting guidance system NowCastMIX (James et al. 2018). HymecNG will also play an important role in the seamless prediction of winter weather events from the current time up to several hours ahead combining observationbased nowcasting and the ensemble based rapid update cycle NWP model within DWD's system SINFONY (Feige et al. 2018).

Acknowledgments. This research was partly funded by Federal Ministry of Transport and Digital Infrastructure (mFUND: 19F2013A). The authors thank their colleagues at the central meteorological application development department for their helpful advice and support. Special thanks go to Paul James for his comments on the manuscript. We also thank the three anonymous reviewers for their insightful comments and suggestions, which greatly improved the manuscript.

\section{REFERENCES}

Al-Sakka, H., A.-A. Boumahmoud, B. Fradon, S. J. Frasier, and P. Tabary, 2013: A new fuzzy logic hydrometeor classification scheme applied to the French X-, C-, and S-band polarimetric radars. J. Appl. Meteor. Climatol., 52, 2328-2344, https:// doi.org/10.1175/JAMC-D-12-0236.1.

American Meteorological Society, 2020a: Graupel. Glossary of Meteorology, accessed 24 March 2021, https://glossary.ametsoc. org/wiki/Graupel.

_- 2020b: Standard atmosphere. Glossary of Meteorology, accessed 24 March 2021, https://glossary.ametsoc.org/wiki/ Standard-atmosphere.

- 2020c: Wet-bulb temperature. Glossary of Meteorology, accessed 24 March 2021, https://glossary.ametsoc.org/wiki/Wetbulb-temperature.

Augter, G., Ed., 2013: Vergleich der Referenzmessungen des Deutschen Wetterdienstes mit automatisch gewonnenen Messwerten. Berichte des Deutschen Wetterdienstes, Vol. 238, 2nd ed. Selbstverlag des Deutschen Wetterdienstes, 64 pp., https://nbn-resolving.de/urn:nbn:de:101:1-201303017676.

Babak, O., and C. V. Deutsch, 2009: Statistical approach to inverse distance interpolation. Stochastic Environ. Res. Risk Assess., 23, 543-553, https://doi.org/10.1007/s00477008-0226-6.

Baldauf, M., C. Gebhardt, S. Theis, B. Ritter, and C. Schraff, 2018: Beschreibung des operationellen Kürzestfristvorhersagemodells COSMO-D2 und COSMO-D2-EPS und seiner Ausgabe in die Datenbanken des DWD. Deutscher Wetterdienst, Offenbach am 
Main, Germany, accessed 9 August 2021, https://www.dwd.de/ SharedDocs/downloads/DE/modelldokumentationen/nwv/ cosmo_d2/cosmo_d2_dbbeschr_aktuell.html.

Baldwin, M., R. Treadon, and S. Contorno, 1994: Precipitation type prediction using a decision tree approach with NMCs mesoscale eta model. Preprints, 10th Conf. on Numerical Weather Prediction, Portland, OR, Amer. Meteor. Soc., 30-31.

Besic, N., J. Figueras i Ventura, J. Grazioli, M. Gabella, U. Germann, and A. Berne, 2016: Hydrometeor classification through statistical clustering of polarimetric radar measurements: A semisupervised approach. Atmos. Meas. Tech., 9, 4425-4445, https:// doi.org/10.5194/amt-9-4425-2016.

Bloemink, H. I., and E. Lanzinger, 2005: Precipitation type from the Thies disdrometer. WMO Tech. Conf. on Instruments and Methods of Observation (TECO-2005), Bucharest, Romania, WMO, 4-7.

Bourgouin, P., 2000: A method to determine precipitation types. Wea. Forecasting, 15, 583-592, https://doi.org/10.1175/15200434(2000)015<0583:AMTDPT>2.0.CO;2.

Brandes, E. A., A. V. Ryzhkov, and D. S. Zrnić, 2001: An evaluation of radar rainfall estimates from specific differential phase. J. Atmos. Oceanic Technol., 18,363-375, https://doi.org/10.1175/ 1520-0426(2001)018<0363:AEORRE > 2.0.CO;2.

Chapman, L., C. Bell, and S. Bell, 2017: Can the crowdsourcing data paradigm take atmospheric science to a new level? A case study of the urban heat island of London quantified using Netatmo weather stations. Int. J. Climatol., 37, 3597-3605, https://doi.org/10.1002/joc.4940.

Deutscher Wetterdienst, 1998: Aspirations-Psychrometer-Tafeln. 7 th ed. Vieweg, $271 \mathrm{pp}$.

- 2018: Vorschriften und Betriebsunterlagen Nr. 2: Wetterschlüsselhandbuch-ASCII-codierte Schlüssel. Deutscher Wetterdienst, Offenbach am Main, Germany, accessed 9 August 2021, https://www.dwd.de/DE/leistungen/pbfb_verlag_vub/ pdf_einzelbaende/vub_2_ascii_barrierefrei.htm.

DIN EN 15518-3:2011-04, 2011: Winter maintenance equipment-Road weather information systems-Part 3: Requirements on measured values of stationary equipments; German version EN 15518-3:2011. Norm, DIN Deutsches Institut für Normung e. V., Berlin, Germany, https://doi.org/10.31030/1719255.

Doms, G., and Coauthors, 2011: A description of the nonhydrostatic regional COSMO-Model. Part II: Physical parameterizations. Deutscher Wetterdienst, Offenbach am Main, Germany, LM_F90 4.20, http://www2.cosmo-model.org/ content/model/documentation/core/cosmo_physics_4.20.pdf.

Elmore, K. L., Z. Flamig, V. Lakshmanan, B. Kaney, V. Farmer, H. D. Reeves, and L. P. Rothfusz, 2014: mPING: Crowdsourcing weather reports for research. Bull. Amer. Meteor. Soc., 95, 1335-1342, https://doi.org/10.1175/BAMS-D-1300014.1.

Fan, Y., and H. Van den Dool, 2008: A global monthly land surface air temperature analysis for 1948-present. J. Geophys. Res., 113, D01103, https://doi.org/10.1029/2007JD008470.

Feige, K., R. Posada, and U. Blahak, 2018: Developing a concept to visualize object-based weather forecasting ensembles. Workshop on Visualisation in Environmental Sciences (EnvirVis), K. Rink et al., Eds., The Eurographics Association, 19-25, https:// doi.org/10.2312/envirvis.20181133.

FGSV, 2019: Hinweise für Planung, Einrichtung und Betrieb von Straßenzustands- und Wetterinformationssystemen (H PEB SWIS). FGSV Verlag GmbH, 28 pp.

Hannak, L., and S. Brinckmann, 2020: Parallelmessungen an deutschen Klimareferenzstationen: Schlussfolgerungen im
Hinblick auf Homogenität und Messunsicherheiten. Berichte des Deutschen Wetterdienstes, Vol. 253, Selbstverlag des Deutschen Wetterdienstes, Offenbach am Main, 101 pp., https://www.dwd.de/DE/leistungen/pbfb_verlag_berichte/pdf_ einzelbaende/253_pdf.pdf?_blob=publicationFile $\& v=4$.

Heizenreder, D., and S. Haucke, 2009: Das meteorologische Visualisierungs-und Produktionssystem NinJo. Promet, 35, 57-69, http://nbn-resolving.de/urn:nbn:de:101:1-2017012510513.

Helmert, K., and Coauthors, 2014: DWDs new radar network and postprocessing algorithm chain. Proc. Eighth European Conf. on Radar in Meteorology and Hydrology (ERAD 2014), Garmisch-Partenkirchen, Germany, DWD and DLR, 4.4, https://www.pa.op.dlr.de/erad2014/programme/ExtendedAbstracts/ 237_Helmert.pdf.

Höller, H., M. Hagen, P. F. Meischner, V. N. Bringi, and J. Hubbert, 1994: Life cycle and precipitation formation in a hybrid-type hailstorm revealed by polarimetric and Doppler radar measurements. J. Atmos. Sci., 51, 2500-2522, https:// doi.org/10.1175/1520-0469(1994)051<2500:LCAPFI>2.0.CO;2.

James, P. M., B. K. Reichert, and D. Heizenreder, 2018: NowCastMIX: Automatic integrated warnings for severe convection on nowcasting time scales at the German Weather Service. Wea. Forecasting, 33, 1413-1433, https:// doi.org/10.1175/WAF-D-18-0038.1.

Joe, P., H.-J. Koppert, D. Heizenreder, B. Erbshaeusser, W. Raatz, B. Reichert, and M. Rohn, 2005: Severe weather forecasting tools in the NinJo workstation. World Weather Research Programme's Symp. on Nowcasting and Very Short Range Forecasting, Toulouse, France, WMO, 7.13, http://meteo.fr/ cic/wsn05/resumes-longs/7.13-502.pdf.

Keeter, K. K., and J. W. Cline, 1991: The objective use of observed and forecast thickness values to predict precipitation type in North Carolina. Wea. Forecasting, 6, 456-469, https://doi.org/ 10.1175/1520-0434(1991)006<0456:TOUOOA > 2.0.CO;2.

Koppert, H.-J., T. Pederson, B. Zürcher, and P. Joe, 2004: How to make an international workstation project successful. 20th Int. Conf. on Interactive Information and Processing Systems (IIPS) for Meteorology, Oceanography, and Hydrology, Seattle, WA, Amer. Meteor. Soc., 11.1, https://ams.confex.com/ams/ 84Annual/techprogram/paper_71789.htm.

Liu, H., and V. Chandrasekar, 2000: Classification of hydrometeors based on polarimetric radar measurements: Development of fuzzy logic and neuro-fuzzy systems, and in situ verification. J. Atmos. Oceanic Technol., 17, 140-164, https://doi.org/ 10.1175/1520-0426(2000)017<0140:COHBOP > 2.0.CO; 2 .

Meier, F., D. Fenner, T. Grassmann, M. Otto, and D. Scherer, 2017: Crowdsourcing air temperature from citizen weather stations for urban climate research. Urban Climate, 19, 170-191, https://doi.org/10.1016/j.uclim.2017.01.006.

Park, H. S., A. Ryzhkov, D. Zrnić, and K.-E. Kim, 2009: The hydrometeor classification algorithm for the polarimetric WSR-88D: Description and application to an MCS. Wea. Forecasting, 24, 730-748, https://doi.org/10.1175/2008WAF2222205.1.

Pflüger, U., 2019: Wetter-Interpretation für die Modelle ICON/ ICON-EU und COSMO-D2. Deutscher Wetterdienst, Offenbach am Main, Germany, accessed 24 March 2021, https://www.dwd.de/DE/forschung/wettervorhersage/num modellierung/01_num_vorhersagemodelle/01c_wetterinterpretation/ wetter_interpretation.pdf?_blob=publicationFile \&v $=6$.

Ramer, J., 1993: An empirical technique for diagnosing precipitation type from model output. Fifth Int. Conf. on Aviation Weather Systems, Vienna, VA, Amer. Meteor. Soc., 227-230. 
Reeves, H. D., K. L. Elmore, A. Ryzhkov, T. Schuur, and J. Krause, 2014: Sources of uncertainty in precipitation-type forecasting. Wea. Forecasting, 29, 936-953, https://doi.org/10.1175/WAFD-14-00007.1.

— A. A. Ryzhkov, and J. Krause, 2016: Discrimination between winter precipitation types based on spectral-bin microphysical modeling. J. Appl. Meteor. Climatol., 55, 1747-1761, https:// doi.org/10.1175/JAMC-D-16-0044.1.

Ritter, B., and J.-F. Geleyn, 1992: A comprehensive radiation scheme for numerical weather prediction models with potential applications in climate simulations. Mon. Wea. Rev., 120, 303-325, https://doi.org/10.1175/1520-0493(1992)120<0303: ACRSFN $>2.0 . \mathrm{CO} ; 2$.

Rolland, C., 2003: Spatial and seasonal variations of air temperature lapse rates in Alpine regions. J. Climate, 16, 1032-1046, https:// doi.org/10.1175/1520-0442(2003)016<1032:SASVOA >2.0.CO;2.

Scheuerer, M., S. Gregory, T. M. Hamill, and P. E. Shafer, 2017: Probabilistic precipitation-type forecasting based on GEFS ensemble forecasts of vertical temperature profiles. Mon. Wea. Rev., 145, 1401-1412, https://doi.org/10.1175/MWR-D16-0321.1.

Schraff, C., H. Reich, A. Rhodin, A. Schomburg, K. Stephan, A. Perianez, and R. Potthast, 2016: Kilometre-scale ensemble data assimilation for the COSMO model (KENDA). Quart. J. Roy. Meteor. Soc., 142, 1453-1472, https://doi.org/10.1002/qj.2748.

Schuur, T. J., H.-S. Park, A. V. Ryzhkov, and H. D. Reeves, 2012: Classification of precipitation types during transitional winter weather using the RUC model and polarimetric radar retrievals. J. Appl. Meteor. Climatol., 51, 763-779, https:// doi.org/10.1175/JAMC-D-11-091.1.

—, A. V. Ryzhkov, H. D. Reeves, J. Krause, K. L. Elmore, and K. L. Ortega, 2014: Recent modifications to a new surface-based polarimetric hydrometeor classification algorithm for the WSR-88D network. Proc. Eighth European Conf. on Radar in Meteorology and Hydrology (ERAD2014), Garmisch-Partenkirchen, Germany, DWD and DLR, 7.5, https://www.pa.op.dlr.de/ erad2014/programme/ExtendedAbstracts/134_Schuur.pdf.

Scott, R. D., P. R. Krehbiel, and W. Rison, 2001: The use of simultaneous horizontal and vertical transmissions for dualpolarization radar meteorological observations. J. Atmos. Oceanic Technol., 18, 629-648, https://doi.org/10.1175/15200426(2001)018<0629:TUOSHA > 2.0.CO;2.

Seifert, A., 2002: Parametrisierung wolkenmikrophysikalischer Prozesse und Simulation konvektiver Mischwolken. Ph.D. thesis, Department of Physics, University of Karlsruhe,
Germany, 240 pp., https://www.imk-tro.kit.edu/download/ SEIFERT2002a.pdf.

Straka, J. M., D. S. Zrnić, and A. V. Ryzhkov, 2000: Bulk hydrometeor classification and quantification using polarimetric radar data: Synthesis of relations. J. Appl. Meteor., 39, 1341-1372, https://doi.org/10.1175/1520-0450(2000)039<1341: BHCAQU $>2.0 . \mathrm{CO} ; 2$.

Thompson, E. J., S. A. Rutledge, B. Dolan, V. Chandrasekar, and B. L. Cheong, 2014: A dual-polarization radar hydrometeor classification algorithm for winter precipitation. J. Atmos. Oceanic Technol., 31, 1457-1481, https://doi.org/10.1175/ JTECH-D-13-00119.1.

Tiedtke, M., 1989: A comprehensive mass flux scheme for cumulus parameterization in large-scale models. Mon. Wea. Rev., 117, 1779-1800, https://doi.org/10.1175/1520-0493(1989)117<1779: ACMFSF $>2.0 . \mathrm{CO} ; 2$.

Werner, M., 2014: A new radar data post-processing quality control workflow for the DWD weather radar network. Proc. Eighth European Conf. on Radar in Meteorology and Hydrology (ERAD2014), Garmisch-Partenkirchen, Germany, DWD and DLR, DAC.P04, https:/www.pa.op.dlr.de/erad2014/programme/ ExtendedAbstracts/079_Werner.pdf.

— the DWD polarimetric C-band weather radar network. Proc. Seventh European Conf. on Radar in Meteorology and Hydrology (ERAD2012), Toulouse, France, Meteo-France, http://www.meteo.fr/cic/meetings/2012/ERAD/extended_abs/ NET_403_ext_abs.pdf.

World Meteorological Organization, 2019: Manual on Codes. International Codes. Volume I.1. Annex II to the WMO Technical Regulations. Part A-Alphanumeric Code. Vol. 306, WMO, World Meteorological Organization, $480 \mathrm{pp}$.

Yang, L., M. Chen, X. Wang, L. Song, M. Yang, R. Qin, C. Cheng, and S. Li, 2021: Classification of precipitation type in North China using model-based explicit fields of hydrometeors with modified thermodynamic conditions. Wea. Forecasting, 36, 91107, https://doi.org/10.1175/WAF-D-20-0005.1.

Zhang, J., and Coauthors, 2011: National mosaic and multi-sensor QPE (NMQ) system: Description, results, and future plans. Bull. Amer. Meteor. Soc., 92, 1321-1338, https://doi.org/ 10.1175/2011BAMS-D-11-00047.1.

_ , and Coauthors, 2016: Multi-radar multi-sensor (MRMS) quantitative precipitation estimation: Initial operating capabilities. Bull. Amer. Meteor. Soc., 97, 621-638, https://doi.org/ 10.1175/BAMS-D-14-00174.1. 